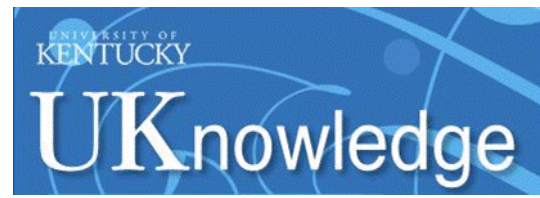

University of Kentucky UKnowledge

\title{
7-2013
}

\section{Metal-Based Nanoparticle Interactions with the Nervous System: The Challenge of Brain Entry and the Risk of Retention in the Organism}

Robert A. Yokel

University of Kentucky, ryokel@email.uky.edu

Eric A. Grulke

University of Kentucky, eric.grulke@uky.edu

Robert C. Macphail

U.S. Environmental Protection Agency

Right click to open a feedback form in a new tab to let us know how this document benefits you. Follow this and additional works at: https://uknowledge.uky.edu/ps_facpub

Part of the Chemical Engineering Commons, Medical Toxicology Commons, and the Pharmacy and Pharmaceutical Sciences Commons 


\title{
Metal-Based Nanoparticle Interactions with the Nervous System: The Challenge of Brain Entry and the Risk of Retention in the Organism
}

\author{
Digital Object Identifier (DOI) \\ https://doi.org/10.1002/wnan.1202
}

\section{Notes/Citation Information}

Published in Wiley Interdisciplinary Reviews: Nanomedicine and Nanobiotechnology, v. 5, issue 4.

Copyright (C) 2013 Wiley Periodicals, Inc.

The copyright holder has granted the permission for posting the article here.

This is the peer reviewed version of the following article:

Yokel, R., Grulke, E., \& MacPhail, R. (2013). Metal-based nanoparticle interactions with the nervous system: The challenge of brain entry and the risk of retention in the organism. Wiley Interdisciplinary Reviews: Nanomedicine and Nanobiotechnology, 5(4), 346-373, which has been published in final form at https://doi.org/10.1002/wnan.1202

This article may be used for non-commercial purposes in accordance with Wiley Terms and Conditions for Use of Self-Archived Versions. This article may not be enhanced, enriched or otherwise transformed into a derivative work, without express permission from Wiley or by statutory rights under applicable legislation. Copyright notices must not be removed, obscured or modified. The article must be linked to Wiley's version of record on Wiley Online Library and any embedding, framing or otherwise making available the article or pages thereof by third parties from platforms, services and websites other than Wiley Online Library must be prohibited. 
Metal-based nanoparticle interactions with the nervous system: the challenge of brain entry and the risk of retention in the organism

Yokel, Robert; University of Kentucky,

Grulke, Eric; University of Kentucky, Chemical \& Materials Engineering MacPhail, Robert; U.S. EPA, Neurotoxicology Division

\section{I.SCOPE OF THE REVIEW}

II. THE NERVOUS SYSTEM: A PROTECTED ORGAN

III. COLLOIDAL CHEMISTRY INFLUENCES "WHAT THE CELL SEES"

III.A. Colloidal (and nanoparticle) dispersion stability

III.B. Electrostatic stabilization

III.C. Stabilization systems

III.C.1. Surfactants and micelles

III.C.2. Coupling agents

III.C.3. Polymers for steric protection

IV. ENVIRONMENTAL FACTORS THAT INFLUENCE "WHAT THE CELL SEES"

IV.A. Milieu pH

IV.B. Solubility

V. METAL-BASED NANOPARTICLES AND THE NERVOUS SYSTEM: SCOPE OF THE KNOWLEDGE

VI. ROUTES OF AND BARRIERS TO BRAIN NANOPARTICLE UPTAKE

VI.A. Nanoparticle uptake through the blood-brain barrier

VI.B. Sites lacking an intact blood-brain barrier

VI.C. Nanoparticle uptake through the choroid plexuses

VI.D. Direct uptake into the brain through cranial nerves exposed to the environment

VI. E. Direct introduction of nanoparticles into the brain

VII. THE PHARMACOKINETICS OF BRAIN NANOPARTICLE UPTAKE AND DISTRIBUTION

VII.A Nanoparticle factors that influence central nervous system (CNS) uptake

VII.A.1. Size

VII.A.2. Shape

VII.A.3. Surface charge (in relation to luminal surface of brain endothelial cells)

VII.A.4. Surface coating (intended and opsonization)

VII.B. Subcellular nanoparticle localization

VIII. THE PHARMACODYNAMICS OF NANOPARTICLES IN THE NERVOUS SYSTEM

VIII.A. Blood-brain-barrier responses to nanoparticles

VIII.B. Animal responses to nanoparticles

VIII.C. Nervous system responses to nanoparticles not seen in the nervous system

VIII.D. Physical-chemical factors that affect biological responses

VIII.D.1. Size

VIII.D.2. Shape

VIII.D.3. Surface charge

VIII.D.4. Surface coating 
IX. NANOPARTICLE NERVOUS SYSTEM INTERACTIONS OUTSIDE OF THE BRAIN

IX.A. The blood-peripheral nerve barrier to nanoparticle uptake into the peripheral nervous system (PNS)

IX.B. Nanoparticle effects on the spinal cord and peripheral nervous system

$X$. IN VITRO STUDIES WITH BRAIN-DERIVED CELLS

XI. VALIDATION THAT IN VITRO APPROACHES PREDICT IN VIVO EFFECTS

XII.NANOPARTICLE INTERACTION WITH INFRA-MAMMALIAN ANIMAL SPECIES (ZEBRAFISH, C. ELEGANS, AND DROSOPHILA)

Sidebar 1: Pharmacokinetics of gold nanoparticle nervous system entry, influencing factors, and extent of entry

Sidebar 2: Gold nanoparticle nervous system pharmacodynamics

XIII. CONCLUSIONS AND RESEARCH NEEDS

XIV. REFERENCES

\begin{tabular}{|c|c|}
\hline & \\
\hline BBB & blood-brain barrier \\
\hline BCSFB & blood cerebrospinal fluid barrier \\
\hline BMEC & brain microvascular endothelial cells \\
\hline BNB & blood-nerve barrier \\
\hline BRB & blood-retinal barrier \\
\hline CSF & cerebrospinal fluid \\
\hline CT & computed tomography \\
\hline CNS & central nervous system \\
\hline DRG & dorsal root ganglia \\
\hline GFAP & glial fibrillary acidic protein \\
\hline LOEL & lowest observable effect level \\
\hline MRI & magnetic resonance imaging \\
\hline NOEL & no observable (observed) effect leve \\
\hline NP & nanoparticle \\
\hline NS & nervous system \\
\hline PAMAM & poly(amido amine) \\
\hline PEG & polyethylene glycol \\
\hline PNS & peripheral nervous system \\
\hline QD & quantum dot \\
\hline ROS & reactive oxygen species \\
\hline SPION & superparamagnetic iron oxide NP \\
\hline TEM & transmission electron microscopy \\
\hline & atertial \\
\hline
\end{tabular}




\begin{abstract}
This review of metal- and metal-oxide-based nanoparticles focuses on factors that influence their distribution into the nervous system, evidence that they enter brain parenchyma, and nervous system responses. Emphasis is placed on gold as a model metal-based nanoparticle and for risk assessment in the companion review. The anatomy and physiology of the nervous system, basics of colloid chemistry, and environmental factors that influence what cells see are reviewed to provide background on the biological, physical-chemical, and internal milieu factors that influence nervous system nanoparticle uptake. The results of literature searches reveal little nanoparticle research has included the nervous system, which about equally involved in vitro and in vivo methods, and very few human studies. The routes of uptake into the nervous system and mechanisms of nanoparticle uptake by cells are presented with examples. Brain nanoparticle uptake inversely correlates with size. The influence of shape has not been reported. Surface charge has not been clearly shown to affect flux across the blood-brain barrier. There is very little evidence for distribution of metal-based nanoparticles into brain parenchyma. Metal-based nanoparticle disruption of the bloodbrain barrier and adverse brain changes have been shown, and are more pronounced for spheres than rods. Study concentrations need to be put in exposure contexts. Work with dorsal root ganglion cells and brain cells in vitro show the potential for metal-based nanoparticles to produce toxicity. Interpretation of these results must consider the ability of nanoparticles to distribute across the barriers protecting the nervous system of the intact organism. Effects of the persistence of poorly soluble metal-based nanoparticles are of particular concern.
\end{abstract}




\section{SCOPE OF THE REVIEW}

Much has been reported on polymer-based drug delivery systems that target the brain. A prior review in this forum focused on carbon-based and quantum dot (QD) nanoparticles (NPs) ${ }^{1}$. This review of the English language literature of metal and metaloxide based NPs $(\leq 100 \mathrm{~nm})$ focuses on the factors that influence their distribution into the brain, evidence that they enter brain parenchyma, and their biological responses. NPs are being investigated as delivery systems to the brain, including MRI contrast agents, photosensitizers for diagnosis, labeling, tumor site identification, and as therapeutic agents, especially to treat cancer. Industrial applications include: fuel cells, batteries, nanocomposites, coatings, and catalysts. This review has relevance for risk assessment of metal-based NPs with the central nervous system (CNS).

Risk assessment requires information on NP characterization, fate, accumulation, translocation, release, and effects. A critical issue for risk assessment is whether current in vitro and in vivo results are based on solid knowledge of the dose characteristics and mechanisms for adsorption, distribution, metabolism, and elimination 2. The present review provides some background for these conundrums, emphasizing gold as a model NP. Data for gold NPs are used as a model for risk assessment in the companion review ${ }^{2}$. Core NP physical-chemical characterization properties include chemical composition and impurities, crystallinity, shape, and morphology/chemistry of surface functional groups (intentional coatings and/or agents that become associated with the NP surface, including proteins, surfactants and environmental colloids such as humic acids). The roadmap of this review is the nervous system (NS) as a protected organ, the colloidal chemistry of NPs, and the pharmacokinetic and pharmacodynamic interactions of NPs with the NS.

\section{THE NERVOUS SYSTEM: A PROTECTED ORGAN}

There is concern that NPs may compromise the NS which has properties that render it uniquely susceptible to insult. The NS is divided into the central NS (CNS) comprised of the brain and spinal cord, and peripheral NS (PNS), comprised of 12 pairs of cranial and 31 pairs of spinal nerves that connect the CNS to organs, muscles and glands. Outgoing (effector) neurons mediate motor activity and autonomic activity. Incoming (sensory) neurons provide visual, hearing, smell/taste, proprioception (body position), and pain/itch information. The afferent neurons pass through the spinal nerve dorsal root ganglia (DRG), comprised of neuronal cell bodies that lie along the back of the vertebral column (spine). The CNS has many sites of specialized function.

The CNS is enclosed in 3 meninges (the dura, arachnoid and pia membranes). Cerebrospinal fluid (CSF) fills a compartment comprised of 4 ventricles within the brain, a canal within the spinal cord, and the sub-arachnoid space between the arachnoid and pia membranes that surrounds the brain and spinal cord,. This fluid-filled compartment dampens mechanical shock to the CNS. Most CSF is produced by choroid plexuses in the brain's 4 ventricles. Some comes from brain extracellular (interstitial) fluid, that comprises $20 \%$ of the brain volume, flowing along capillary and artery walls, into the brain's ventricles. Drainage of fluid and substances from the human brain is primarily via CSF, giving the opportunity to indirectly monitor the brain's biochemical activity. Most CSF drains into blood through the arachnoid villi, although a small percentage drains 
into the lymphatic system ${ }^{3}$. Lymphatic system drainage accounts for a greater percentage of fluid drainage from the brain in rats, rabbits and sheep. Lymphatic drainage from rat brain into cervical lymph nodes was demonstrated with a dextrancoated 20 to $200 \mathrm{~nm}$ superparamagnetic iron oxide NP (SPION) and MRI ${ }^{4}$.

There are 2 cell types in the normal brain, neurons and glial cells. Although generally thought that there are 10-fold more glial cells than the $\sim 100$ billion neurons in the human brain, the ratio may not be this great, and may be close to $1^{5-8}$. Glia include the macroglia (neuroglial cells, of neural origin) which are astrocytes and oligodendrocytes, and the microglia. Neurons are thought to be post-mitotic in most mammalian brain regions. They are particularly sensitive to insult because of their high metabolic requirements and long processes (axons up to a meter long, and dendrites) with large surface areas that depend on the cell body for protein synthesis and much metabolism. The human brain is $2 \%$ of the typical body mass but receives $15 \%$ of the blood, utilizes $20 \%$ of the body's resting oxygen and energy consumption, and is fueled largely by transporter influx of glucose. The macroglia have a negative resting membrane potential, but do not propagate action potentials. They are physically connected by gap junctions to from a functional network. Glial cells express voltage-gated ion channels similar to those seen in neurons, are able to express receptors to many of the same neurotransmitters and neuromodulators as neurons, have transporters to take up many neurotransmitters, and can release some neurotransmitters. Astrocytes play a role in regulation of neuro- and gliogenesis, neuronal path finding and regulation of synaptogenesis; form the scaffold of the NS; contribute to and regulate the BBB; regulate cerebral microcirculation; provide energy substrates for neurons; and provide a favorable extracellular milieu by regulating extracellular potassium and $\mathrm{pH}$ and taking up neurotransmitters. The oligodendrocytes in the CNS have 4 to 6 processes that produce myelin which insulates axons between nodes of Ranvier, assisting fast saltatory action potential propagation. Schwann cells in the PNS myelinate axons and also perform some functions that astrocytes perform. Microglia, of monocyte/macrophage lineage, are resident immune cells, entering the brain during embryogenesis. In the normal brain they are in the resting state. They have numerous receptors and immune molecule recognition sites. The glial response to insults is reactive gliosis. It is manifest as astrocyte hypertrophy and proliferation, causing increased synthesis of its cytoskeletal intermediate filament glial fibrillary acidic protein (GFAP) and axonal degeneration (Wallerian degeneration), due to loss of myelination. In response to many stressors, including injury, inflammation, infection, lipopolysaccharide, foreign matter, and brain implants, as well as reduction of normal brain activity, microglia can be activated to a reactive state within hours, upregulating potassium channels, down-regulating neuronal and upregulating immunocompetent receptors, increasing enzyme synthesis, and increasing surveillance of brain activity. Some proceed to become phagocytic microglia. Microglial over-activation can contribute to neuronal damage and neurodegenerative disorders ${ }^{5}$. For more background on brain cells see ${ }^{5,9}$.

\section{COLLOIDAL CHEMISTRY INFLUENCES "WHAT THE CELL SEES"}

As noted by ${ }^{10}$, "Nanoparticles in solution are called colloids." A review of colloid chemistry provides insight into NP physical-chemical properties that impact their uptake, distribution, pharmacodynamics, dosimetrics, and biological fate ${ }^{11-14}$. In a colloidal 
system one substance is microscopically dispersed throughout another. The dispersed phase particles are usually 1 to $1000 \mathrm{~nm}$. The dispersed and continuous phases may be gas, liquid, or solid (except a gas/gas system which is miscible and would not be considered a colloid). The stability of colloidal dispersions (that is, whether they remain as discrete particles or agglomerate, aggregate, or flocculate) depends on whether the discrete phase surface chemistry renders a thermodynamically stable dispersion in the continuous phase. ${ }^{1}$

\section{A. Colloidal (and nanoparticle) dispersion stability}

Forces that affect the stability of colloidal systems include: excluded volume repulsion (hard particles cannot overlap), electrostatic interaction (colloid particles often carry electric charge and can repel or attract one another), van der Waals forces (permanent or induced dipoles in particles can repel or attract), entropic forces (systems of particles will tend to maximize entropy, leading to interparticle forces), and steric interactions (polymers adsorbed to surfaces can provide physical barriers that prevent close approach of potentially attractive charges). Mutual repulsion of like electrical charges on NP colloids leads to electrostatic stabilization. Steric stabilization of colloids occurs when coatings such as polymers or oligomers are attached to NP surfaces; these coatings prevent them from approaching close enough that attractive forces would become effective, thus preventing agglomeration. Many commercial NP products have surface coatings/functionalizations that are designed to control their dispersion in specific media. These materials are referred to as complex NPs ${ }^{15}$ or nanocomplexes ${ }^{16}$, terms increasingly used in the literature.

\section{III.B. Electrostatic stabilization}

Charge stabilization is an important way to control coalescence of colloidal dispersions 11. Colloidal stability is usually defined as the tendency for particles to agglomerate/aggregate or form sediment. Electrostatic stabilization is based on charged double layers that develop around colloid particles in polar liquids. The charge on the surface of the colloid induces opposite charges in the local liquid. The charged region can extend some distance from the hard particle surface, and can be quite sensitive to salt concentrations, ion types (multivalent ions in particular), and $\mathrm{pH}$. This is shown in Figure 1, that illustrates two solid colloidal particles (gray spheres), that have a negative surface charge, in a dispersion. Positive ions (pink) form a dense layer near the negatively charged solid surfaces. These ions attract negative ions (blue) via coulombic forces, forming a second, more diffuse layer. Interfacial double layers are important for

\footnotetext{
${ }^{1}$ Agglomerate: A collection of weakly bound particles or aggregates or mixtures where the resulting external surface area is similar to the sum of the surface areas of the individual components http://www.iso.org/obp/ui/\#iso:std:iso:ts:80004:-4:ed-1:v1:en (accessed 8-14-2012).

Aggregate: A particle composed of strongly bonded or fused particles where the resulting external surface area may be significantly smaller than the sum of calculated surface areas of the individual components http://www.iso.org/obp/ui/\#iso:std:iso:ts:80004:-4:ed-1:v1:en (accessed 8-14-2012).

Flocculant: In chemistry this is a process wherein colloids come out of suspension in the form of floc or flakes by the addition of a clarifying agent. The action differs from precipitation in that prior to flocculation colloids are merely suspended in a liquid and not actually dissolved in a solution. In the flocculated system, there is no formation of a cake, since all the flocs are in the suspension (www.wikipedia.com).

Coalescence: A process in which two phase domains (droplets, bubbles or particles) of the same composition come together and form a larger phase domain http://en.wikipedia.org/wiki/Coalescence (accessed 8-14-2012).
} 
systems with large ratios of surface area to volume. The total potential energy of interaction for a pair of colloid particles in solution is linked to attractive (e.g., van der Waals) and repulsive forces. Attractive forces have been modeled by Hamaker and de Boer; this potential energy is directly proportional to the particle radius and the Hamaker constant (describing the interaction between the particle and the continuous phase), and inversely proportional to the inter-particle separation distance ${ }^{11}$.

Electrostatic repulsion forces stabilize particles in aqueous or polar organic media. The zeta-potential ( $\zeta$ ) of the colloid can be used as a measure of the thickness of the double layer, as shown in Figure 1. Zeta potential measurements are used to estimate the double layer charge. The small graph on the right hand side of Figure 1 shows the change in electrical potential at various distances from the colloid surface. Voltage gradients $(\mathrm{V} / \mathrm{m})$ can be very steep in the vicinity of colloids, which affects their stability in the dispersion. The $\zeta$ potential, which is calculated using theoretical models and experimentally-determined electrophoretic mobilities, is the electrical potential in the double layer between the 'slipping layer' (denoted by the outer black dashed line) and a point in the bulk fluid. The total $\zeta$ potential is taken to be the linear addition of the attractive and repulsive forces. This function usually has a maximum, creating an activation energy for agglomeration. For agglomeration to occur, two particles must collide with sufficient energy to overcome this barrier. Inside the slipping layer, the local fluid, including ions, moves with the colloidal particle. In Figure 1, the positive ions induced toward the negative charges on the colloid surface have a gradient that decreases rapidly with distance due to the negative ions moving in from the bulk solution. A system with a high absolute value of the $\zeta$ potential, $>40 \mathrm{mV}$ for example, has high repulsive charges at the point where local fluid moves relatively independently from the particle. Such a system should be electrically stable, and resistant to agglomeration, coagulation, or flocculation. Electrostatic stabilization provides kinetic but not thermodynamic 'stability', which always tends toward agglomeration/aggregation. Stability can be influenced by salt concentration, ion type, $\zeta$ potential, and particle size ${ }^{11}$. As the salt concentration increases, the double layer thickness decreases and more collisions will lead to agglomeration. For example, a 30 $\mathrm{mM}$ sodium chloride $(\mathrm{NaCl})$ solution has a double layer thickness of $2 \mathrm{~nm}$, while a 0.1 $\mathrm{mM} \mathrm{NaCl}$ solution has a double layer thickness of $30 \mathrm{~nm}$. When multivalent ions are present the electrolyte concentration needed for coagulation can decrease by orders of magnitude. Repulsive energy is proportional to the square of the measured $\zeta$-potential; these values are often used to tune a dispersion to attain kinetic stability. In general, a larger particle radius leads to a higher energy barrier.

\section{III.C. Stabilization systems}

There are a variety of stabilization systems used for NP dispersions, including surfactants, coupling agents, and polymers. Each of these stabilization systems can have specific responses to subtle changes in the NP's environment, reducing uncertainty about long-term stability of these dispersions.

\section{III.C.1. Surfactants and micelles}

Surfactants, by lowering the surface tension between two phases, can be used to form micelles by surrounding a material that is insoluble in a medium to enable its 
introduction into that medium. Surfactants usually protect the growing particle surface. Surfactants used in water dispersions are usually amphiphilic. They adsorb at interfaces, such as NP/liquid interfaces. However, surfactants are usually reversibly adsorbed to NP surfaces, and can desorb as milieu conditions change. Some surfactants can affect cell processes and are toxic.

\section{III.C.2. Coupling agents}

Coupling agents are commonly used to modify NPs for use in a variety of solvents and polymers. The most common coupling agents are based on silane chemistry. Many reactive groups and non-reactive ligands are available commercially. As with any reactive system, it is useful to know the surface density of the reactive group on the NPs. Covalent bonding to the surfaces of NPs is sensitive to the physical-chemical properties of their surface and the reaction environment ${ }^{12}$.

\section{III.C.3. Polymers for steric protection}

Polymer adsorption to NPs depends on polymer charge and molecular weight, and the aqueous solution conditions ( $\mathrm{pH}$, ionic strength and salts). The polymer may have a variety of conformations on the surface; the electrostatic forces around the complex particle may be altered, and steric forces may be the major component of the repulsive forces. Reorientation of the polymer chains near the surface can occur with changes in environmental conditions. See ${ }^{13}$ for a good review.

Polymeric NPs (inverse microemulsions) are being developed for drug delivery applications, carrying hydrophobic drugs in the micelle interior to specific body sites ${ }^{14}$. For example, coating complex NPs with polyethylene glycol (PEG) surfactants makes their surface hydrophilic, which can lengthen the time the NP circulates in blood ${ }^{17}$. Particles with sizes less than $100 \mathrm{~nm}$ seem to be particularly well-suited for this purpose (for an example see ${ }^{18}$ ).

\section{ENVIRONMENTAL FACTORS THAT INFLUENCE "WHAT THE CELL SEES" IV.A. Milieu pH}

The milieu $\mathrm{pH}$ can influence the NP chemical species, including surface charge and solubility. It can also affect colloid (NP) stability and fate. For the mammal, some relevant $\mathrm{pHs}$ are in Table 1. The upper gastrointestinal tract and lysosomes are most likely to affect NP chemical species.

\section{IV.B. Solubility}

Solubility can influence the chemical species and effects of NPs. Insoluble ceria-, goldand titania-based NPs have pharmacokinetics, localization, and effects that are different from their soluble forms ${ }^{1}$. This becomes less clear for NPs that are soluble at physiological pHs, such as copper, iron, silver, and zinc oxide. The following examples illustrate this. Dissolution of QDs, often composed of a cadmium selenide, cadmium sulfide, or cadmium selenide tellurium core, releases the toxic metal cadmium ${ }^{19}$. Transmission electron microscopy (TEM) and scanning TEM failed to reveal $\sim 2.2 \mathrm{~nm}$ PEG-coated silver NP in the brain 24 to 168 hours after its intraperitoneal injection, whereas inductively coupled mass spectrometry (ICP-MS) showed the presence of silver, presumably due to dissolution and silver ion brain entry ${ }^{20}$. All of the toxicity of a 
zinc oxide NP was thought to be due to solubilized zinc ${ }^{21}$. Metal-based NP distribution is often assessed using destructive elemental analysis techniques, such as "bulk" (e.g. $50 \mathrm{mg}$ ) tissue digestion and analysis by ICP-MS; ICP-atomic emission spectroscopy or ICP-optical emission spectrometry; graphite furnace (electrothermal, flameless) atomic absorption spectrometry; instrumental neutron activation analysis; or radioactive analysis. These techniques do not differentiate between intact NP and dissolved metal. PEG, mercaptoacetic acid, and zinc sulfide coatings have been used to reduce toxicity, but they do not always prevent dissolution ${ }^{22}$.

\section{METAL-BASED NANOPARTICLES AND THE NERVOUS SYSTEM: SCOPE OF THE KNOWLEDGE}

Literature searches were conducted to identify numbers of publications and patents about nanoparticles (a SciFinder® search of the concept "nanoparticle" from 1990 through 2011). The typical search string started with the term, 'nanoparticles', and then was refined by material composition (i.e., gold, carbon black, metals, etc.) or study type (in vitro or in vivo). The publication count includes all scientific inquiries while the patent counts point toward commercialization activities. The results are shown in Figures 2 and 3. Nanoparticle, in vitro NP and in vivo NP publications had $32 \%, 28 \%$, and $30 \%$ exponential growth rates, respectively (Figure $2 \mathrm{~A}$ ). However, the total NP publications far exceed those focused on biological systems, reflecting the small percentage of total effort focused on biological benefits and risks. For example, in 2011, there were 51,806 publications on nanoparticles, with $2960(6 \%)$ linked to in vitro studies and $2575(5 \%)$ linked to in vivo studies. To understand the extent of reports on NPs and the NS, SciFinder® searches were conducted using the terms neuron, nerve, glial cell, astrocyte, oligodendrocyte, and microglia paired with nanomaterial and nanoparticle. The results were reviewed for studies of metal-based NPs. Two hundred fifty-five reports were found. This is $0.1 \%$ of the NP literature, showing that remarkably few studies of biological effects of metal-based NPs included NS endpoints. The metal(s) and research platform(s) (in vitro and/or in vivo) were identified in each report in our literature searches. Figure 2 (Panel B) shows the predominant metal NPs and research platforms used (Panel C).

A major use of metal-based NPs is as imaging agents, including SPIONs and QDs. SPIONS have been investigated for imaging by MRI or combined with a fluorescent or optical dye in a multimodal nanoplatform for cell labeling, including neural stem cells that have tropism for glioblastomas, magnetic thermotherapy induced by alternating magnetic field activation, and external field magnetic targeting. NP surface modification with agents specific for brain tumors increases tumor targeting ${ }^{23}$. Capitalizing on their intense fluorescent emission, QD-conjugated probes have been used to recognize glycine, $\mathrm{GABA}_{A}$ and tyrosine kinase $B$ receptors, epidermal growth factor receptor, nerve growth factor, brain tumors, glutamate transporters, cell surface membrane and fusion proteins, and GFAP; label mammalian CNS neural stem and progenitor cells, microtubules, GFAP intermediate filament cellular bridges, and aquaporin-4 and P2 receptors; and visualize endocytosis. Some of these have been visualized using single molecule/particle imaging/tracking. Much of the work so far has been demonstration of proof of principle. NS-related demonstrations have been mostly conducted in cells in 
culture, often PC12 cells (derived from a rat adrenal pheochromocytoma; used as a neuron model).

The clinical applications most often addressed utilized SPIONs for NS visualization by $\mathrm{MRI}$, cell labeling, and thermotherapy. This has focused on brain cancer ${ }^{24}$ and been suggested for axon regeneration following NS injury ${ }^{25}$. Ceria NPs have been suggested to be a potential anti-oxidant therapeutic agent for neurodegenerative disease ${ }^{26}$, but this has not yet been demonstrated in the intact animal. Studies of metal-based NPs given to humans to target the NS have been conducted by only a few groups, focusing on the use of iron oxide as a tumor imaging agent ${ }^{27,28}$ and in magnetic thermotherapy treatment of glioma ${ }^{24,29}$. To predict the future of NP applications, the number of issued patents for NPs is shown in Figure 3, as well as those containing metal-based NPs and selected metals. For example, there were 7182 nanoparticle patents issued in 2011. Silica- and titania-containing NPs have generally been the focus of more patents than gold and silver, suggesting more future commercial applications of the former two.

\section{ROUTES OF AND BARRIERS TO BRAIN NANOPARTICLE UPTAKE}

The major routes of NP uptake in the human are from the respiratory tract (including the nasal cavity), gastrointestinal tract, and potentially through the skin. Uptake can lead to distribution into the central compartment (blood) from which the NP can distribute into the NS across the blood-brain barrier (BBB), blood-cerebrospinal fluid barrier (BCSFB) and blood-nerve barrier (BNB). In addition there is a direct route to the brain via cranial nerves that are exposed to the environment (see: VI.D. Direct uptake into the brain through cranial nerves exposed to the environment). Absorption of metal-based NPs from the oral cavity has been demonstrated ${ }^{30}$. NP absorption from the colon and rectum has been described, but not for metal-based NPs. Sublingual NP absorption has not been well demonstrated. Absorption from the stomach and intestine is related to NP size ${ }^{30}$. Nano titania has been the most studied metal-based NP for dermal uptake due to its use in sun screen products. In the absence of damage to the skin, organic solvents and irritant detergents, or skin flexing, there is little evidence of metal-based NP systemic absorption after dermal application ${ }^{31}$.

Hurdles to overcome for NP delivery to the brain from blood include the BBB (discussed in VI.A. Nanoparticle uptake through the blood-brain barrier) and the clearance of NPs through distribution, metabolism, and excretion processes that reduce the amount available to enter the brain. A high percentage of NPs are cleared from circulation by the mononuclear phagocyte system. Increasing NP delivery to the brain might be addressed by increasing the NP dose. This presents the risk of increasing undesirable effects and presenting an even greater NP body burden that creates concern about the long-term effects of persistent NPs. Another approach is the use of PEG and other surface modifications to render the NP less recognizable by the mononuclear phagocyte system. More targeted approaches include surface modification to enhance selective uptake into the target site, e.g., functionalization recognized only by glioma cells when treating that condition, the use of magnetic NPs directed to the target brain site by external field targeting, and short-term opening of the BBB. These approaches are discussed below. 
Further hurdles to brain delivery are metabolism and elimination. Metabolism is greatly influenced by the NP chemical composition, with solubility a significant issue, discussed in IV.B. Solubility. Another major issue of metabolism is opsonization, discussed in VII.A.4 Surface coating (intended and opsonization). Molecules $<3 \mathrm{~nm}$ are freely filtered through the kidney's glomerular capsule; those $>5 \mathrm{~nm}(\sim 70 \mathrm{kDa})$ are not. QDs $<5 \mathrm{~nm}$ were renally eliminated ${ }^{32}$.

When "bulk" tissue is used to determine NP distribution, and efforts are not made to remove blood from the animal, the NP in the blood within the tissue contributes to the bulk tissue NP content. ${ }^{14} \mathrm{C}$-sucrose very slowly diffuses across the intact BBB and is used as an indicator of vascular space. Based on ${ }^{14} \mathrm{C}$-sucrose in the brain immediately after its i.v. administration, compared to its blood concentration, the vascular volume of gray matter, white matter, the frontal lobe, cerebellum, and pituitary were calculated to be $2.7,1.1,2.1,3.5$, and $26.8 \%$, respectively ${ }^{33}$. Figure 4 shows results of reports where selected, quite insoluble, metal-based NPs were investigated in "bulk" brain which reported NP as \% of the dose or from which it could be calculated. Many NPs were either not seen in the brain or poorly entered the brain, which is $~ 0.5 \%$ of rat and $1.75 \%$ of mouse body weight. These results are consistent with a recent statement that "less than $0.1 \%$ of inhaled or systemically injected nanoparticles are found within the brain" ${ }^{34}$. With such limited penetration, one might be inclined to discount the CNS as a target for metal-based NPs, but the literature indicates otherwise.

\section{VI.A. Nanoparticle uptake through the blood-brain barrier}

The CNS is insulated from many changes in the body by the BBB and BCSFB; the PNS by the BNB. These barriers present a formidable challenge to delivery of substances into the NS and create a pharmacological sanctuary. The anatomical basis of the BBB includes the brain microvascular endothelial cells (BMECs) that line the $\sim 5$ to $10 \mu \mathrm{m}$ diameter vessels that perfuse the brain. Their surface area $\left(20 \mathrm{~m}^{2}\right)$ is 10 -fold greater than that of the human body. Unlike the endothelial cells that line capillaries in most body regions, they are joined by tight junctions that severely limit paracellular flux. Brain vascular endothelial cells have little bulk (fluid) phase endocytosis or receptor-mediated endocytosis, and generally lack fenestrations. They have, however, considerable metabolic activity. They are surrounded by a basement membrane, which is covered by pericytes on $\sim 30 \%$ of its surface. Astrocyte foot processes cover $>95 \%$ of this complex. Rapid flux of substances between blood and brain is possible due to the extensive distribution of microvessels (which are within $\sim 15 \mu \mathrm{m}$ of any cell in the brain) ${ }^{35}$. Sialic acid residues on the BBB luminal surface provide a negative charge, which is expected to influence the ability of charged NPs to approach the BBB ${ }^{36}$. Most brain entry, quantitatively, and the most rapid kinetically, is across the BBB. The mechanism of metal-based brain NP uptake across the intact BBB is believed to be transcytosis through the BMECs ${ }^{37-39}$. Opening of the BBB for $<1 \mathrm{~h}$, typically using $25 \%$ mannitol infused into a carotid artery, has been used to increase drug delivery to the brain ${ }^{40}$. This approach has not been reported with metal-based NPs. Focused ultrasound BBB disruption has been used to open the BBB for a few hours to enhance chemotherapeutic-magnetic NP brain delivery ${ }^{41,42}$. Direct uptake into the brain through cranial nerves exposed to the environment provides another route, discussed below. 


\section{VI.B. Sites lacking an intact blood-brain barrier}

The rodent BBB begins to develop pre-natally. Intraperitoneal injection of 25 to $70 \mathrm{~nm}$ anatase titania to mice on gestational days $3,7,10$, and 14 resulted in titania in the olfactory bulb and cerebral cortex and apoptosis in the olfactory bulb of 6 week old male offspring. The NP presumably distributed into the brain before BBB development was sufficient to prevent it ${ }^{43}$. Given the insolubility of titania, the brain distribution and effects were presumably due to intact NP.

There are sites lacking the BBB, which allow chemical communication between blood and brain, including the periventricular organs, the chemoreceptor trigger zone, and DRG. Forty $\mathrm{nm}$ latex microspheres were detected in vagal sensory ganglia a week after their intra-tracheal instillation, suggesting uptake from the lung ${ }^{44}$. This creates the possibility of further distribution into the NS by retrograde (from the axon terminal toward the cell body) axonal transport, as seen with polio and other retroviruses. No reports were found assessing the relative ability of NPs to enter the brain at these locations normally lacking an intact BBB compared to those that have a BBB.

\section{VI.C. Nanoparticle uptake through the choroid plexuses}

The structural basis of the brain's BCSFB is the epithelial cell layer of the choroid plexuses in the brain's 4 ventricles. Reports of metal-based NP interaction with the choroid plexus are limited to uptake of organic surface-coated iron oxides ${ }^{45-47}$. Characterization of the size and other properties of NPs that enable their distribution through the tight junctions of the choroid plexus epithelial cells has not been determined. The steady state CSF/serum ratio appears to be the best available parameter to characterize drug penetration into the CSF ${ }^{48}$. The most relevant data, of steady state protein in human lumbar CSF and blood serum, suggest the entry of a compound into the CSF depends on the square root of its molecular mass ${ }^{49}$. Extrapolation from the protein results suggests CSF concentration would be $\sim 0.5$ and $0.25 \%$ of blood serum concentration for 4 and $10 \mathrm{~nm} \mathrm{NPs}$. No reports of distribution into, or effects of metal-based NPs on, CSF were found other than a report showing measureable cerium in CSF up to 90 days after a single i.v. administration of $30 \mathrm{~nm}$ ceria ${ }^{50}$.

\section{VI.D. Direct uptake into the brain through cranial nerves exposed to the environment}

The only sites where the NS is directly exposed to the environment are nerve endings of the olfactory nerves in the roof of the nasal cavity and the trigeminal nerve maxillary division in the nasal cavity and roof of the mouth. Uptake from the nasal cavity into the olfactory nerve, olfactory bulb, and across synapses to connecting neurons of the brain was shown with $50 \mathrm{~nm}$ colloidal silver-coated gold ${ }^{51}$. Translocation of $\sim 35 \mathrm{~nm}{ }^{13} \mathrm{C}$ carbon particles along the olfactory pathway, and to a lesser extent into the cerebrum and cerebellum 1 to 7 days later, was shown ${ }^{52}$. Rats exposed by inhalation to $\sim 30 \mathrm{~nm}$ manganese agglomerates had up to a 3.5-fold increase of manganese in the olfactory bulb, and lower (but significant) increases in 4 brain regions. Increases in gene and protein expression indicative of inflammatory changes were most pronounced in the olfactory bulb ${ }^{53}$. Lectin-functionalized, polymer-coated, $95 \mathrm{~nm}$ QDs were taken up into the brain following their nasal instillation ${ }^{54}$. Whole-body inhalation exposure to spherical 
gold (primary particle size $\sim 20 \mathrm{~nm}$, airborne median size $\sim 78 \mathrm{~nm}, 2 \times 10^{6}$ particles $/ \mathrm{cm}^{3}$ ) for 5 days significantly increased olfactory, septum, entorhinal cortex (the latter two areas have direct neuronal connections from the olfactory bulb), and cerebellum (that might have been bathed by gold in the CSF) gold 15 days later. However, given this exposure route, the gold NPs might have entered systemic circulation from the nasal cavity or lung and entered these brain regions through the BBB. There was no verification that the gold in the brain was as gold NP, but due to its insolubility, this is likely ${ }^{55}$. On the other hand, whole-body inhalation exposure to spherical gold (4 to 5 $\mathrm{nm}, \sim 2.4 \times 10^{4}, 2.4 \times 10^{5}$, or $1.8 \times 10^{6}$ particles $/ \mathrm{cm}^{3}$ ) 6 hours/day, 5 days/week for 90 days did not increase olfactory bulb gold, and only increased brain gold in female rats exposed to the highest concentration ${ }^{56}$.

Toxic effects of intranasal NP administration have been reported. Intranasal application of aqueous dispersions of $0.5 \mathrm{mg} 80 \mathrm{~nm}$ rutile and $155 \mathrm{~nm}$ anatase titania every other day for a month resulted in a time-dependent increase of titanium in the olfactory bulb, cerebral cortex, hippocampus, and cerebellum; 25 to $30 \%$ cell loss in the hippocampal CA1 stratum pyramidale region; increased pro-oxidant effects; and neuronal pathology 30 days later. Given the insolubility of titania NP, it was assumed the effects were due to its translocation into the brain ${ }^{57,58}$. Ferric oxide NPs $(21 \mathrm{~nm})$ given by intranasal instillation entered the axon of olfactory bulb neurons and produced significant prooxidant effects, dendrite degeneration, and membrane structure disruption in the olfactory bulb, and an increase of hippocampal lysosomes ${ }^{59}$. Similar repeated instillation of 22 or $33 \mathrm{~nm}$ ferric oxide caused microglial cell activation and increased BV2 microglial cell generation of reactive oxygen species (ROS) and generation of nitric oxide but not cytokines, in vitro ${ }^{60}$. Intra-nasal lipopolysaccharide-functionalized cadmium selenide QDs activated microglia and increased nitric oxide generation, as might be anticipated with the endotoxin ${ }^{61}$. Intranasal instillation of gold rods produced a biphasic microglial activation that was greater than the monophasic activation produced by gold nano-urchins (gold NPs with small attached spines). Spheres produced little effect ${ }^{62}$. More details of these NPs are below (VIII.D. 2 Physical-chemical factors that affect biological responses, Shape). Every other day intranasal application of 33 to 380 $\mathrm{nm}$ silver for 2 weeks resulted in defects in spatial cognition (Morris water maze) and long-term potentiation and increased hippocampal ROS. In the absence of brain silver determination or demonstration of silver NP in the brain, the absorption route and chemical species absorbed (NP vs. silver ion) are unknown ${ }^{63}$.

A simulation model of 1 to $100 \mathrm{~nm}$ NP deposition (undefined composition and density) to the rat's nasal cavity and olfactory region using computational fluid dynamics to assess particle size uptake dependence showed 95,20 , and $2 \%$ deposition in the nasal cavity of the 1,10, and $100 \mathrm{~nm}$ NPs. Deposition to the olfactory region was maximal for 3 to $4 \mathrm{~nm} \mathrm{NPs}$, mostly in the anterior nose ${ }^{64}$. Direct uptake into human brain from the nasal cavity might be less than in the rat due to the smaller percentage of the nasal mucosa innervated by the olfactory nerve ( $5 \mathrm{vs}$. $50 \%$ ) and because the human is not an obligate nasal breather ${ }^{65}$. However, results of a model suggest the concentration of a $20 \mathrm{~nm}$ particle may be greater in the human, than rat, olfactory bulb ${ }^{65}$. 
Injection of colloidal radiolabeled gold under the mucous membrane of the rabbit's nasal roof resulted in the highest gold concentration in the CSF withdrawn most closely from the site of injection. It was presumably taken up through the perivascular space around the olfactory nerve, presenting another route of uptake from the nasal cavity into the cranium ${ }^{66}$.

\section{E. Direct introduction of nanoparticles into the brain}

Metal-based NPs have been directly injected into the brain, bypassing the above barriers. One approach is convection-enhanced delivery (CED) that employs a pump to produce a pressure gradient to deliver an agent directly to the target (often tumor) site via an implanted cannula ${ }^{23}$. NPs containing metals as imaging agents have been studied by CED. Iron oxide NPs, enabling MRI-image guidance, have been conjugated to an epidermal growth factor antibody or albumin and methotrexate to treat glioblastoma multiforme tumors ${ }^{67,68}$. CED of QDs to rat brain was not visualized by clinical computed tomography (CT) or MRI in the live rat, but could be visualized in excised fixed brain by high-resolution, small animal CT ${ }^{69}$.

\section{THE PHARMACOKINETICS OF BRAIN NANOPARTICLE UPTAKE AND DISTRIBUTION}

The mechanisms of substance distribution into the brain include diffusion, carriermediated transport, and receptor-mediated processes (facilitated diffusion, active transport, and endocytosis [cell absorption by engulfing particles and receptor mediated uptake in small vesicles into a cell]) ${ }^{70}$. A study with perfused 1 to $1.2 \mathrm{~nm}$ lanthanum did not show flux through the BBB endothelial cell tight junctions of 1 to 14 day old rats ${ }^{71}$. Diffusion across the BBB favors small molecules $\left(<500 \mathrm{D}_{\mathrm{a}}, \sim 1 \mathrm{~nm}\right)$ and lipophilic substances. Endocytotic processes involve macropinocytosis, caveolae, clathrin-coated pits, caveolae/clathrin-independent uptake, and phagocytosis. Caveolar uptake occurs in non-fenestrated endothelial cells, involving an invagination of the cell membrane surrounded by the protein caveolin on the cytoplasmic surface, receptor proteins, and invagination into the cell. The caveolae-mediated uptake pit diameter is $\sim 50$ to $80 \mathrm{~nm}$. Uptake requires cellular stimulation. The clathrin-coated pit diameter is $\sim 120 \mathrm{~nm}$. An example is transferrin binding to its receptor. Phagocytosis can engulf spherical particles from $\sim 0.2$ to $3 \mu \mathrm{m}$ into a vacuole. The BBB expresses many influx and efflux transporters; most substrates are small molecules ${ }^{72}$. NPs might hitchhike through the BBB on peptide transporters such as transferrin - the molecular trojan horse approach. No reports of transporter-mediated brain uptake of metal-based NPs were found. A study using the in situ brain perfusion technique showed that 2 minutes after carotid arterial perfusion of $5 \mathrm{~nm}$ ceria NP it was associated with the luminal wall of BMECs, but had not entered those cells or brain parenchyma. Given more time, the NPs might cross the BBB ${ }^{39}$. Six hours after intraperitoneal injection captopril-conjugated QDs were frequently seen in brain blood vessels but only occasionally in perivascular areas and brain parenchyma of cerebral cortex, thalamus and olfactory bulb ${ }^{73}$, consistent with the very limited flux of metal-based NPs across the BBB (Figure 4).

Endocytotic processes are believed to be the major mechanism of NP cell uptake. They are much slower than small molecule diffusion or transporter-mediated uptake, demonstrated by clathrin-mediated uptake half-lives of $2.02,1.88$, and 2.52 hours for 
14,50 , and $74 \mathrm{~nm}$ transferrin-coated gold into SNB19 (brain tumor) cells ${ }^{74}$. Metalbased NPs shown to be taken up by endocytosis include 6 to $20 \mathrm{~nm}$ silver NPs into human glioblastoma (U251) cells ${ }^{75}$ and $\sim 77 \mathrm{~nm}$ gold urchins into N9 microglia 62 . Uptake of $70 \mathrm{~nm}$ silver NP into rat BMECs may have been mediated by transcytosis ${ }^{38}$. A role for clathrin was shown in the uptake of $120 \mathrm{~nm}$ L-DOPA-coated iron oxide into rat brain capillary endothelial and choroidal plexus epithelial cells, and 40 and $200 \mathrm{~nm}$ carboxylated polystyrene NPs into an astrocytoma cell line ${ }^{46,76}$.

Based on results of studies with gold nanospheres, nanorods and nano-urchins (see VII.B. Subcellular nanoparticle localization) Hutter et al ${ }^{62}$ suggested relatively thin rods may have a more favorable morphology for cell internalization than the other two forms. This may relate to the observation that nanorods enter cells perpendicularly to their long axis ${ }^{77}$. Results suggest endocytotic processes mediate NP uptake into BMECs.

\section{VII.A Nanoparticle factors that influence central nervous system (CNS) uptake VII.A.1. Size}

Smaller NPs enter the brain to a greater extent than larger ones. Figure 5 shows results from several studies with various sizes of gold NPs, different surface functionalizations, and using three different experimental methods. It appears that size, not charge, influenced their permeation differences. Brain uptake results in Panels A through E do not inform whether the NPs entered brain parenchyma or were confined to the vascular compartment, the issue addressed in Figure 4. In a rat BMEC and astrocyte co-culture, $2.8 \%$ of $70 \mathrm{~nm}$ spherical silver NP vs. $0.1 \%$ of $12 \mu \mathrm{m}$ silver particles crossed this in vitro BBB model and 34 vs. $8 \%$ were associated with the BBB cells, respectively ${ }^{38}$. Silver NP flux was quantitatively much greater than in vivo reports of brain metal-based NP uptake. This illustrates, along with Figure 5 Panel $\mathrm{H}$ (permeation through a co-culture model of the BBB) compared to Figure 4 (lack of brain parenchymal uptake of PEGcoated gold NP), the greater leakiness of in vitro BBB models than the mammalian in situ BBB.

After i.v. injection of 20 and $100 \mathrm{~nm}$ gold NPs only the smaller NPs were observed by TEM in retinal neurons, endothelial cells, and peri-endothelial glial cells, suggesting permeation of the blood-retinal barrier (BRB) ${ }^{78}$. The $\mathrm{BRB}$ is comprised of endothelial cells, pericytes, astrocytes, and tight junctions between epithelial cells. Bypassing the BRB, intra-vitreal injection of various NPs has been shown effective to treat angiogenesis-related blindness, retinal degeneration, and uveitis ${ }^{79}$.

There was initially slightly more gold in the brain of mice after a single intraperitoneal injection of 17 than $37 \mathrm{~nm}$ (surface charge - 46 to $-48 \mathrm{mV}$ ) gold NPs. Brain gold increased over 21 days, possibly due to continued absorption or re-distribution from other sites ${ }^{80}$. Brain gold 24 hours after an intragastric administration of $1.4,5,18$, and $80 \mathrm{~nm}$ radiolabeled gold was $\sim 0.0003,0.0001,0.0015$, and $0.0001 \%$ of the dose. The differences could be due to absorption or BBB permeation ${ }^{81}$. Intravenous administration of mono-sulfonated triphenylphosphine gold NPs $(1.4,5,18$, and $80 \mathrm{~nm},-20$ to -23 $\mathrm{mV}$; and $200 \mathrm{~nm},-41 \mathrm{mV}$ ) resulted in uptake that correlated with the volumetric specific surface area for the 1.4 to $18 \mathrm{~nm} \mathrm{NPs}$, but not the larger ones 24 hours later (Figure 4) 
82. Evidence was not provided that the NPs entered brain parenchyma. This study appears to be the only one assessing the dose metric that best describes NP brain uptake, NP size.

There may be an optimal size for NP uptake by brain cells. A diameter of $55 \mathrm{~nm}$ produces the fastest wrapping time for a membrane to enclose a particle, and therefore greatest uptake by endocytosis ${ }^{74}$. The optimal particle diameter to accelerate protein wrapping of cylindrical and spherical particles, and their interaction with the lipid bilayer of cell membranes, was found to be 30 and $60 \mathrm{~nm}$, respectively ${ }^{83}$. Smaller particles might enter cells as agglomerates. A review of the physical-chemical effects of inorganic NPs in relation to their size concluded that NPs with diameters of $30 \mathrm{~nm}$ or less have characteristics that enhance their interfacial reactivity, giving them properties different from their bulk components ${ }^{84}$. This critical size for NPs, at which new properties typically appear, is strongly related to the exponential increase in the number of atoms localized at the surface ${ }^{84}$. For 5 to $100 \mathrm{~nm}$ citrate-coated gold NPs, the maximal association constant with albumin and histone was seen with the $60 \mathrm{~nm}$ particles; with fibrinogen it was the 60 and $100 \mathrm{~nm}$ particles. NP association was considerably greater with globulins and insulin and increased with NP size ${ }^{85}$.

\section{VII.A.2. Shape}

No reports were found addressing the influence of NP shape on brain uptake in intact organisms.

\section{VII.A.3. Surface charge (in relation to luminal surface of brain endothelial cells)}

The luminal to abluminal flux of neutral $60 \mathrm{~nm}$ maltodextrin NPs across a co-culture of bovine BMECs and rat astrocytes was $\sim 3$-fold greater than anionic or cationic NPs. When coated with a dipalmitoyl phosphatidyl choline and cholesterol lipid bilayer, flux of the charged NPs increased 3- to 4-fold, whereas flux of the uncharged did not change 86. The binding of $60 \mathrm{~nm}$ maltodextrin NPs without, and with, a surface cationic ligand $(+25 \mathrm{mV})$, and cationic NPs with an anionic phospholipid (dipalmitoyl phosphatidyl glycerol) in the core to give DPPG-NPs (+24 mV) to bovine BMECs was studied. The cationic NP bound mainly around the paracellular area, the neutral NPs mainly on the cell surface, and DPPG-NPs to both sites. There was no difference in flux of the neutral and cationic NPs across a co-culture of bovine BMECs and mixed glial cells. Flux was inhibited by filipin, showing dependence on the caveolae pathway ${ }^{87}$. Rat brain uptake of a $127 \mathrm{~nm}$ anionic $(-60 \mathrm{mV})$ surfactant surface-coated emulsifying wax NP increased above that seen with a $75 \mathrm{~nm}(-14 \mathrm{mV})$ less anionic or a $97 \mathrm{~nm}(+45 \mathrm{mV})$ cationic NP. The order of disruption to BBB integrity was cationic $>$ anionic $>$ neutral NPs ${ }^{88}$. Mouse brain contained more positively-charged $362 \mathrm{~nm}{ }^{99 \mathrm{~m} T e c h n e c t i u m-l a b e l e d ~ e t o p o s i d e-}$ incorporated tripalmitin than $391 \mathrm{~nm}$ negatively charged NPs after their i.v.

administration ${ }^{89}$. However, there was no demonstration in the prior 2 studies that the NPs crossed the BBB; they could have adsorbed on the luminal wall of, or been sequestered in, the BMECs. The percent of the dose in rat brain of positively charged (cysteamine-coated) $2.8 \mathrm{~nm}$ gold NPs was somewhat greater than negatively charged (thioglycolic acid coated) ones 24 hours after their i.v. administration (Figure 4) ${ }^{82}$. The authors suggest alterations of the NP surface due to protein binding and exchange were major mechanisms determining their accumulation in various organs and tissues. Gold 
was seen in the brain after intragastric administration of a positively charged $\left(\mathrm{NH}_{3}{ }^{+}\right) 2.8$ $\mathrm{nm}$ gold NP ( $0.00015 \%$ of the dose) but not after a negatively charged (COO-) $2.8 \mathrm{~nm}$ one. The site causing the difference could be oral absorption or BBB permeation ${ }^{81}$. Conjugation of a $12 \mathrm{~nm}$ gold NP with an amphipathic peptide (CLPFFD) increased brain distribution 4-fold compared to citrate-capped gold NP of the same size after their intraperitoneal injection. The former had a smaller negative charge (-41 vs. $-52 \mathrm{mV})$ and was more hydrophobic. It did not alter BBB integrity and had no effect on cell viability ${ }^{90}$. No reports that clearly showed an influence of surface charge of metal-based NPs on flux across the BBB were found.

\section{VII.A.4. Surface coating (intended and opsonization)}

The surface of an NP is never naked. Due to high energetic adhesive forces close to the surface, NPs can agglomerate or adsorb to the next available biological or nonbiological surface ${ }^{91}$. In vivo coating by the several thousand proteins in blood or lipids (opsonization) is extremely important, because the NP surface is what cells see ${ }^{92,}, 93$. NP coating can alter size, surface charge, and biological effects ${ }^{94,95}$. There is rapid (within seconds) association with the most abundant proteins that shifts over time to those with the highest affinity constant, i.e., protein sorption is often reversible. Some proteins promote phagocyte clearance. Others, such as albumin and apolipoprotein, prolong NP circulation time. The latter also interacts with BBB receptors to enhance BBB transport. Cell membrane surfaces are negatively charged. Surface coating of polymer NPs has been shown to influence their brain uptake ${ }^{96}$. NP size, shape, and surface area can influence interactions with proteins and cell components $97-99$. The binding of plasma proteins to silica, Aeroxide ${ }^{\circledR}$ P25 (Evonik Degussa $~ 80 \%$ anatase $20 \%$ rutile titania), and zinc oxide NPs was NP-dependent. For titania (the only NP tested for the effect of shape), qualitatively more proteins bound to nanospheres than nanorods or nanotubes ${ }^{100}$. Multilayer protein binding has been observed between 5,10 , $20,30,60,80$, and $100 \mathrm{~nm}$ citrate-coated gold NPs and 5 plasma proteins. Association was assessed using dynamic light scattering to estimate the apparent particle size of the dispersions. Maximal association with albumin and histone was seen with the $60 \mathrm{~nm}$ particles. With fibrinogen it was the 60 and $100 \mathrm{~nm}$ particles. It was considerably greater with globulins and insulin and increased with NP size ${ }^{85}$. The association altered protein conformation; potentially contributing to toxicity. By comparing uncoated (hydroxyl functionalized, that favors caveolar endocytosis), cationic polymer polyethyleneiminecoated (that favors adsorptive-mediated endocytosis), and prion protein-coated $500 \mathrm{~nm}$ silica matrix magnetic core NPs in an in vitro BBB model, it was demonstrated that charge and protein ligands affect their mode of internalization, transcytotic potential, and intracellular localization ${ }^{101}$. NP size and shape therefore influence the proteins that coat them in vivo.

\section{VII.B. Subcellular nanoparticle localization}

When metal-based NPs have been localized in brain cells, they have usually been seen in the cytoplasm, sometimes in vesicles, of microglia. However, there are reports of intra-nuclear distribution. Two $\mathrm{nm}$ QDs were localized to the cytoplasm of N9 murine microglial cells, whereas $5 \mathrm{~nm}$ QDs were in the nucleus ${ }^{103}$. Twenty to $50 \mathrm{~nm}$ pegylated QDs injected into mouse brain were in microglial lysosomes, but not microglial mitochondria or nuclei, or neurons ${ }^{104}$. Degussa P25 titania was seen in microglia 
vacuoles 18 hours after in vitro exposure ${ }^{105}$. Silver NPs (6 to $20 \mathrm{~nm}$ ) were visualized to be uniformly distributed, including in the nucleus, of U251 human glioblastoma cells ${ }^{75}$. In contrast, peptide-coated $20 \mathrm{~nm}$ silver NPs, taken up by astrocytes in vitro, were seen in cellular compartments, most likely lysosomes ${ }^{106}$. Cetyl trimethylammonium bromide (CTAB)-coated gold spheres and rods internalized into N9 microglia acidic lysosomal compartments, whereas PEG-coated gold spheres and rods did not significantly internalize. CTAB- and PEG-coated gold nano-urchins equally internalized, primarily into cytosol. In contrast, CTAB- and PEG-coated gold nano-rods decorated the dendrites and were internalized in the neurites and cell body of primary hippocampal neurons whereas gold spheres and nano-urchins did not ${ }^{62}$. After their intraperitoneal injection $17 \mathrm{~nm}$ gold NPs were seen in the cytoplasm of hippocampal pyramidal cells, surrounded by coated pit-like structures, suggesting endocytotic uptake, whereas $37 \mathrm{~nm}$ gold NP did not enter neurons ${ }^{80}$. NP size and surface coating therefore affect NP subcellular distribution in NS cells.

\section{VIII.THE PHARMACODYNAMICS OF NANOPARTICLES IN THE NERVOUS SYSTEM}

VIII.A. Blood-brain-barrier responses to nanoparticles

A cationic $(97 \mathrm{~nm},+45 \mathrm{mV})$ emulsifying wax NP increased brain cerebrovascular volume to a greater extent than an anionic one $(127 \mathrm{~nm},-60 \mathrm{mV})$, which was greater than a neutral NP $(75 \mathrm{~nm},-14 \mathrm{mV})$. These results suggest cationic NPs were most disruptive to BBB integrity and that neutral and low-concentration anionic colloidal NPs provide a better benefit-safety profile for drug delivery to the brain ${ }^{88}$. A comparable study with metal-based NPs was not found. Administration of $\sim 50 \mathrm{~nm}$ silver, $\sim 50 \mathrm{~nm}$ copper, or $\sim 60 \mathrm{~nm}$ aluminum NP intraperitoneally (50 mg/kg), intravenously (30 mg/kg), carotid arterially $(2.5 \mathrm{mg} / \mathrm{kg})$, and intracerebroventricularly $(20 \mu \mathrm{g}$ in $10 \mu \mathrm{l})$ opened the BBB in rats and mice, demonstrated by Evans blue-albumin brain entry and $1.2 \mathrm{~nm}$ lanthanum extravasation. Brain edema, neuronal (distorted cell shape, chromatolysis and degeneration, nuclear damage, eccentric nucleolus and sponginess) and glial (reactive gliosis and perivascular gliosis, myelin loss, myelin vesiculation) changes were seen. The effects were greater with the silver than the copper, which was greater than the aluminum NP, and greater in the cerebellum than brainstem than hippocampus and cortex, than thalamus and hypothalamus. The work did not show NP entry into parenchyma ${ }^{107,108}$. The results demonstrate metal NPs can damage the BBB and cause adverse brain changes. To test the hypothesis that stress can increase NPinduced brain pathology, 7 daily intraperitoneal injections of the $\sim 50 \mathrm{~nm}$ silver and copper NPs were compared to saline in rats whole-body exposed to $38^{\circ} \mathrm{C}$ for $4 \mathrm{~h}$. The silver NPs increased BBB disruption and brain edema and produced cognitive and motor impairment more than copper NP injections ${ }^{109}$.

Opening the BBB by injection of i.v. mannitol enabled brain entry of dimercaptosuccinic acid-coated $4 \mathrm{~nm}$ iron oxide ${ }^{110}$, consistent with the approach of disrupting the BBB with hyper-osmotic mannitol to enhance brain uptake of therapeutic agents ${ }^{90,111}$. Following large $(50,250$, or $750 \mathrm{mg} / \mathrm{kg})$ i.v. doses of a commercial $\sim 30 \mathrm{~nm}$ ceria, increased brain Evans blue and fluorescein were seen 1 and 20 hours later, but these increases were seldom statistically significant, suggesting minimal disruption of BBB integrity ${ }^{112,} 113$. 
An in vitro study with human BMECs exposed to alumina NPs showed dose- and timedependent reduction of viability, loss of mitochondrial potential, increased superoxide production, and reduced tight junction protein (JAM-A, ZO-1 and ZO-2) expression ${ }^{114}$. I.v. administration of alumina NP $(29 \mathrm{mg} / \mathrm{kg})$ to rats produced claudin -5 and occludin loss, suggesting they have the potential to compromise the BBB, perhaps via alterations in mitochondrial function ${ }^{114}$. Exposure of a rat BMEC and astrocyte co-culture to $25 \mathrm{~nm}$ Aeroxide $\circledast$ titania, up to $20 \mu \mathrm{g} / \mathrm{ml}$, concentration-dependently increased ${ }^{14} \mathrm{C}$-sucrose flux (decreased BBB integrity) and decreased the vinblastine efflux/influx ratio (decreased $p$ glycoprotein activity). These effects were much more sensitive to the NP than cell viability, which was not affected up $200 \mu \mathrm{g} / \mathrm{ml}$. The mRNA expression of structural (tight junction), transport (caveolar), and detoxification (multi-drug resistant and breast cancer related) proteins were depressed. Inflammatory gene expression increased. Titania agglomerations were seen in BMEC and glial cells. The results suggest non-lethal adverse effects on BBB function associated with intracellular, but not intra-nuclear, titania NP ${ }^{115}$. An amphipathic peptide-coated $12 \mathrm{~nm}$ gold NP showed higher brain gold content (although maximally only $0.024 \%$ of the dose) than a less negatively charged citrate-coated gold NP (maximally only $0.0048 \%$ of the dose), and no disruption of BBB integrity ${ }^{90}$. These studies suggest brain drug delivery in the absence of significant BBB disruption is possible. However, an in vitro study with rat primary BMECs showed greater pro-inflammatory responses with 25 and $40 \mathrm{~nm}$ than $80 \mathrm{~nm}$ silver NPs that might lead to inflammation-mediated neurotoxicity ${ }^{116}$. Forty and $60 \mathrm{~nm}$ copper NPs $(1.5$ and $3 \mu \mathrm{g} / \mathrm{ml})$ increased primary rat BMEC proliferation but 12.5 to $50 \mu \mathrm{g} / \mathrm{ml}$ decreased it 117 . Twenty-five $\mu \mathrm{g}$ copper NP/ml increased PGE $2, T N F a$, and IL-1 $1 \beta$ release and $15 \mu \mathrm{g} / \mathrm{ml}$ increased BBB permeability; responses similar to those seen with silver NPs ${ }^{116,117}$. The copper NP effects were size independent. It is not known if these effects were due to the copper and silver NPs or if their ions contributed. Determining the relative sensitivity to NPs of measures of disruption of BBB function, such as viability, tight junction integrity, metabolic activity, and immune and inflammatory processes seems warranted.

No reports were found of the assessment of NP effects on the BNB.

\section{VIII.B. Animal responses to nanoparticles}

A slight brain lesion characterized by hippocampal neuronal vacuoles indicating fatty degeneration was seen after a single oral $5 \mathrm{~g} / \mathrm{kg}$ dose of 80 and 155 , but not $20, \mathrm{~nm}$ titania (crystalline form not stated) to mice ${ }^{118}$. Fourteen consecutive daily intraperitoneal injections of $5,10,50,100$, or $150 \mathrm{mg} / \mathrm{kg}$ of $5 \mathrm{~nm}$ anatase titania to mice dosedependently increased brain titanium (more than a comparable dose of non-NP titania), and increased many pro-oxidant endpoints, indicating oxidative stress ${ }^{119}$. Daily oral administration of this material for 60 days impaired spatial recognition memory after 10 or $50 \mathrm{mg} / \mathrm{kg}$, which was associated with increased titanium, acetylcholine, glutamate, and nitric oxide; decreased norepinephrine, dopamine, serotonin and their metabolites; spongiocyte proliferation; changes in cations; and decreased ATPases in the brain ${ }^{120}$. Intraperitoneal injection of $21 \mathrm{~nm}$ Aeroxide $₫$ titania to mice previously treated with lipopolysaccharide increased ROS and inflammatory cytokines and activated microglia, indicating the potential for NPs to enhance inflammatory brain responses ${ }^{121}$. Nose-only exposure to $22 \mathrm{~nm}$ silver nanoparticles for 6 hour/day 5 days/week for 2 weeks resulted 
in gene product changes, including genes associated with motor neuron and neurodegenerative diseases and immune cell function. The determination of silver or silver NP in the brain was not reported ${ }^{122}$.

\section{VIII.C. Nervous system responses to nanoparticles not seen in the nervous system}

There are reports of NP effects on the NS in the absence of significant NP presence. Potential mechanisms come from related work. Inhalation exposure to fine and ultrafine air pollution particulates increased brain inflammatory markers, which might be explained by either particulate uptake via the olfactory nerve or systemic cytokine release and distribution into the brain ${ }^{123}$. Another mechanism is potential activation of peripheral autonomic or neuronal afferent pathways that result in modulation of CNS activity ${ }^{124}$. NP-induced DNA damage to fibroblasts in vitro was reported in the absence of intracellular NP, mediated by NP interaction with the cell membrane ${ }^{125}$.

\section{VIII.D. Physical-chemical factors that affect biological responses VIII.D.1. Size}

Toxicity to N9 murine microglia was greater from 2.2 than $5.2 \mathrm{~nm}$ diameter cationic QDs 103. Twenty and $50 \mathrm{~nm}$ silver NPs were more toxic to $\mathrm{C} 6$ glioma cells than $100 \mathrm{~nm}$ NPs 126. To assess the physical-chemical properties of NPs that best predict toxicity, doseeffects of 5, 15, 40, and $80 \mathrm{~nm}$ citrate-capped spherical gold NPs were determined in Drosophila melanogaster. Gold NPs decreased lifespan and fertility and increased ROS, heat shock proteins 70 and 83, DNA fragmentation, and apoptosis. Lifespan decreased as NP size decreased, when expressed as NP surface area. Comparing the different sizes, concentration played a primary role in the toxicity; size and surface area did not ${ }^{127,} 128$.

\section{VIII.D.2. Shape}

Gold spheres $(23 \mathrm{~nm})$ coated with CTAB $(42 \mathrm{mV})$ were more toxic to $\mathrm{N} 9$ glial cells than PEG-coated spheres (-23 mV), CTAB- (47 mV) or PEG-coated (-23 mV) nano-rods, or CTAB- $(39 \mathrm{mV})$ or PEG-coated $(-10 \mathrm{mV})$ nano-urchins ${ }^{62}$. PEG-coated spheres and nano-rods, but not PEG- or CTAB-coated nano-urchins, increased N9 granulocyte macrophage colony-stimulating factor whereas PEG- and CTAB-coated nano-urchins increased IL-1 $\alpha$ but PEG-coated spheres and nano-rods did not ${ }^{62}$. Protein-conjugated silver sulfide $\sim 65 \mathrm{~nm}$ spherical NPs inhibited C6 glial cell proliferation to a greater extent than 40 by $200 \mathrm{~nm}$ rods, 50 by $>1000 \mathrm{~nm}$ wires, or bulk crystals ${ }^{129}$. Coating and NP shape can therefore affect glial response. Similarly, $43 \mathrm{~nm}$ gold spheres were more toxic to a non-NS cell line (MDCK II) than 17 by $38 \mathrm{~nm}$ nano-rods ${ }^{130}$.

\section{VIII.D.3. Surface charge}

Twelve $\mathrm{nm}$ magnetite surface coated with silane- $\mathrm{NH}_{2}$ or silane- $\mathrm{COOH}$ was more toxic to C6 glioma, U251, and SHG-44 glioblastoma cells than when coated with meso-2, 3-dimercaptosuccinic acid or silane-short-chain PEG ${ }^{126}$. Although $\zeta$ potentials were not reported, the results suggest surface charge can affect NS cell response to NPs.

\section{VIII.D.4. Surface coating}


Similar gold content of N9 microglia was seen after exposure to CTAB and PEG-coated gold nano-urchins, which was greater than after exposure to CTAB or PEG-coated gold spheres or rods ${ }^{62}$. However, CTAB/trioctylphosphine oxide-coated QDs were toxic to PC12 cells whereas mercaptopropionic acid QDs were not ${ }^{131}$. Citrate-coated iron oxide NPs were more toxic to $\mathrm{C} 17.2$ neural progenitor cells and PC12 cells and increased ROS more than dextran-coated, carboxydextran-coated, or cationic magnetoliposomes 132, 133. Polydimethylamine-coated $\sim 9 \mathrm{~nm}$ core iron oxide NPs reduced the viability of primary cortical neurons from embryonic day 7 chicks to a much greater extent than aminosilane- or dextran-coated particles. Toxicity was associated with removal of the plasma membrane. Their $\zeta$ potential in water and Neurobasal $®$ media (media that support neuronal growth) was $\sim 55$ and $-10 \mathrm{mV} ; 15$ and $10 \mathrm{mV}$; and $\sim 55$ and $-10 \mathrm{mV}$, respectively, illustrating the effects of surface coating on surface charge and toxicity ${ }^{134}$. In contrast, surprisingly, alumina, silica, and tri-methoxy-caprylyl-silane coatings did not modify the toxicity of anatase, rutile, or mixed crystalline form titania to DRG cells ${ }^{135}$. The surface coating of redox-active nanoscale zero-valent iron became more oxidized over 11 months. This "aged" form generated less ROS in MV2 microglia. It reduced viability of MV2 and N27 neuron cells less than the fresh (non-oxidized) NP form ${ }^{102}$.

\section{NANOPARTICLE NERVOUS SYSTEM INTERACTIONS OUTSIDE OF THE BRAIN IX.A. The blood-peripheral nerve barrier to nanoparticle uptake into the peripheral nervous system (PNS)}

Similar to the CNS, neurons in the PNS are protected by the tight junctions and transporters of the endoneurial endothelial cells and pericytes, but no astrocyte foot processes, creating the BNB. Little has been reported on metal-based interactions with the PNS. Nerve growth factor-conjugated QDs were shown to enter DRG neurons and be retrograde axonally transported ${ }^{136}$. Non-functionalized 2 to $3 \mathrm{~nm}$ cadmium telluride QDs were taken up by DRG cells and transported to the cell body by retrograde axonal transport ${ }^{137}$. Silicon dioxide $(<12 \mathrm{~nm})$ NPs were taken up by Schwann, but not DRG, cells ${ }^{138}$.

\section{IX.B. Nanoparticle effects on the spinal cord and peripheral nervous system} Non-functionalized 2 to $3 \mathrm{~nm}$ cadmium telluride QDs taken up by DRG cells produced greater toxicity than their constituent elements and were more toxic to DRG than PC12 cells (as shown by intracellular glutathione depletion and inhibition of neurite outgrowth) 137. Twenty $\mathrm{nm}$ lead oxide particles repeatedly given to rats by intra-tracheal instillation decreased rearing and increased ambulation, increased high-frequency electrocorticogram activity, increased somatosensory cortical evoked potential latency, and decreased conduction velocity in the tail nerve ${ }^{139}$. These results could be due to CNS and/or PNS effects and NP translocation from lung, or to dissolution of the lead oxide. Apoptosis induced by titania (anatase, rutile and mixtures; 11 to $31 \mathrm{~nm}$ ) in chick embryo DRG cells was not abrogated by the several inorganic and organic surface coatings tested ${ }^{135}$; cell uptake was evidently not examined. Anatase titania NPs dosedependently decreased DRG survival to a greater extent than Schwann cells, IC $50 \sim 5$ and $25 \mu \mathrm{g} / \mathrm{ml}$, respectively ${ }^{140}$. Silica $(<12 \mathrm{~nm})$ NP taken up by Schwann cells reduced their survival (IC50 $150 \mu \mathrm{M})$. DRG cells, which did not appear to take up this NP, were less affected ${ }^{138}$. Repeated intraperitoneal injection of 50 to $60 \mathrm{~nm}$ aluminum, copper, and silver NPs exacerbated trauma-induced spinal cord pathology, associated with 
breakdown of the PNS barrier to serum proteins ${ }^{141}$. When applied to the spinal cord 5 minutes after injury, titanium-containing nanowires (with diameters of 50 to $60 \mathrm{~nm}$, surface modified) improved motor function and decreased blood-spinal cord barrier disruption and spinal cord edema ${ }^{142}$. Chitosan-gold NPs enhanced rat sciatic nerve axon repair after injury ${ }^{143}$. Application of 3 to $5 \mathrm{~nm}$ ceria $(10 \mathrm{nM})$ to cultures of spinal cord cells isolated from 3 to 4 month old rats increased the live-to-dead-cell ratio 15 and 30 days later, attributed to an anti-oxidant effect of the nanoceria to scavenge free radicals ${ }^{144}$. As with CNS cells, NPs can enter PNS cells to produce effects that are NPand cell-type dependent.

\section{IN VITRO STUDIES WITH BRAIN-DERIVED CELLS}

There are well recognized advantages and shortcomings of in vitro testing. The complexity of the human NS cannot be adequately modeled in cell culture experiments 145. As noted above, BBB cell culture models do not have the same degree of impermeability as the in situ BBB. Due to the formidable barrier properties of the BBB, in vitro studies of NP uptake and effects are informative, but not necessarily representative of what would be expected in the whole organism. Without understanding the extent of NP penetration into the NS, where the NP could be taken up by neural and glial cells, a complete understanding of the potential benefits and risks is lacking. NP uptake has been shown in NS cells, including astrocytes ${ }^{146,147}$, microglial cells ${ }^{105,148}$, and neurons ${ }^{148}$. Greater uptake of peptide-coated 20 and $40 \mathrm{~nm}$ silver NPs was seen with the astrocytes than neurons of a mixed primary cortical neural cell culture consisting mainly of neurons and astrocytes, with some oligodendrocytes ${ }^{106}$, demonstrating cell type-dependent response.

Many NP effects on NS cells in culture have been reported, illustrating their potential to produce NS cell toxicity. Examples are cadmium tellurium and cadmium selenium QDs on hypothalamic glial, hippocampal neural, N9 microglial, IMR-32 and SH-SY5Y human neuroblastoma, and PC12 cells ${ }^{103,149-152 ;}$; anatase titania, zinc oxide, and magnesium oxide NPs on human glioblastoma astrocytoma U87 cells ${ }^{153}$; and a commercial magnetic NP on microglia ${ }^{154}$. Interpretation of NP uptake by NS cells in vitro and effects of NP exposure results should be couched in terms of the ability of these NPs to distribute across the BBB, BNB, and/or BCSFB into the NS of the intact organism.

Mesenchymal stem cells can undergo neuron-like differentiation. SPIONs were used as MRI contrast agents and to label cells. It was shown possible to label human amniotic membrane-derived mesenchymal stem cells without producing significant toxicity ${ }^{155}$.

\section{VALIDATION THAT IN VITRO APPROACHES PREDICT IN VIVO EFFECTS}

No reports were found that directly addressed validation of in vitro endpoints with in vivo data using NS cells. There are a number of studies that used both in vivo and in vitro models. There was generally decent agreement, suggesting in vitro models may predict in vivo responses.

\section{XII.NANOPARTICLE INTERACTION WITH INFRA-MAMMALIAN ANIMAL SPECIES (ZEBRAFISH, C. ELEGANS, AND DROSOPHILA)}


There may be value in studying small intact organisms that have the full complement of organ systems, require less cost and test material, and have short time spans. They enable developmental, life-span, aging, and multi-generational studies in much less time than traditional mammalian models. The zebrafish, which has $80 \%$ homology to the human genome, has been utilized to study NP developmental effects. Exposure to 5 to $20 \mathrm{~nm}$ bovine serum albumin-capped silver resulted in a few scattered primary particles in the zebrafish embryo brain ${ }^{156}$. Microinjection of anatase titania NP into the otic vesicle produced significant effects on gene regulation ${ }^{157}$. Titanium was found in the brain after titania NP exposure ${ }^{158}$. Anatase titania NP was more toxic to brain biochemical endpoints than its bulk material counterpart ${ }^{159}$. Exposure from 6 to 24 or 48 hours post-fertilization to N,N,N-trimethylammoniumethanethiol (TMAT)-, 2-mercaptoethanesulfonic acid (MES)-, or 2-(2-(2-mercaptoethoxy)ethoxy)ethanol (MEEE)-functionalized $1.5 \mathrm{~nm}$ gold NPs resulted in similar uptake, but greater mortality and genetic effects from TMAT than MES than MEEE, suggesting surface functionalization influenced the differential responses ${ }^{160}$. Nerve impulse transmission gene expression was enhanced. Exposure to titania NP from fertilization to free swimming stage produced adverse behavioral deficits that were more sensitive than hatchability and survival effects ${ }^{161}$. Initial results with zebrafish suggest it predicts effects expected in mammalian organisms.

The adult $C$. elegans hermaphrodite has 302 neurons that belong to two distinct and independent NSs: a large somatic (282 neurons) and a small pharyngeal NS (20 neurons). It has 959 somatic cells. Its genome has been sequenced. Five nM ceria (8.5 $\mathrm{nm}$ ) in the food source increased ROS accumulation and oxidative damage and decreased lifespan. No NS endpoints were reported ${ }^{162}$. Zinc NP and zinc ion produced equipotent effects on movement ${ }^{163}$. More work with this organism will be needed to determine how well it predicts higher organism NS responses.

A study of drosophila response to citrate-capped spherical gold NPs is summarized in VIII.D.1 Size

Sidebar 1: Pharmacokinetics of gold nanoparticle nervous system entry, influencing factors, and extent of entry

To illustrate the current understanding of metal-based NP interaction with the NS, gold was selected because it has been used in many studies of NP distribution into the NS and resultant effects. Its size, shape, purity, and surface functionalization and charge can be easily manipulated during synthesis; it can be quantified by very sensitive analytical methods and visualized by TEM; and it has very low background concentrations. Gold NPs have been surface coated with many agents, including citrate to increase aqueous stability (e.g., the NIST standard reference materials); an amphipathic peptide derived from $\beta$-amyloid ${ }^{90}$; transferrin and PEG to target cancer cells ${ }^{164}$; radioactive iodine and tripeptide-PEG as probes for targeting cancer cells and imaging tumor sites ${ }^{165}$; with epidermal growth factor to enhance brain uptake ${ }^{166 ;}$; gellan gum as a capping and reducing agent and further conjugated with sophorolipids ${ }^{167}$; and encapsulated in a ternary mixture of dioleoylphosphatidylcholine, sphingomyelin, and cholesterol to increase resistance to aggregation ${ }^{168}$. Gold NPs are also insoluble, so levels can be confidentially attributed to the NP. As seen with other NPs, small (4 and 
$13 \mathrm{~nm})$ gold circulated in blood longer than a larger (100 nm) NP and little was excreted in bile or urine 18,50 . The mononuclear phagocyte system sequesters most NPs from the blood, including gold NPs ${ }^{18,82,90,169}$. Elevated brain gold was seen following i.v., inhalation, intraperitoneal, and intragastric gold NP exposure. Brain gold concentration inversely correlated with NP size (Figure 4) ${ }^{82,170,171}$. In the absence of PEG coating, brain gold was usually $\leq 0.01 \%$ of an i.v. dose; PEG coating increased brain uptake, but did not result in preferential gold NP distribution to the brain (Figure 4) ${ }^{171,172}$. Even less gold entered the brain after oral administration due to very low oral NP bioavailability ${ }^{30}$, 81. Positively-charged gold NPs resulted in higher brain gold than negatively charged ones. Clathrin-mediated endocytotic processes mediate gold NP cell uptake, with uptake half-lives of $\sim 2$ hour ${ }^{74}$. Intracellular gold NPs have been seen in the cytosol and lysosomal compartments of neural and glial cells ${ }^{62}$. Repeated intraperitoneal injection of $12 \mathrm{~nm}$ citrate-coated gold resulted in a dose-dependent increase of brain gold 1 day later ${ }^{169}$, consistent with the bioaccumulation of insoluble NPs that are too large to be filtered by the kidney. Bioaccumulation and prolonged retention has been shown with gold ${ }^{18}$ and other insoluble NPs, including ceria ${ }^{50}$, Thorotrast $($ (a colloidal solution of $\geq$ $45 \mathrm{~nm}$ aggregates of thorium dioxide ${ }^{173}$ ), $70 \%$ anatase $30 \%$ rutile titania ${ }^{174}$, and QDs 175

Sidebar 2: Gold nanoparticle nervous system pharmacodynamics Gold NPs are being investigated for imaging, tracking and labeling (including CT, Raman spectroscopy and TEM); as drug and gene delivery carriers; as photothermal/photodynamic therapy agents; sensors; electronic conductors; and catalysts ${ }^{166,176-179}$. Although insoluble, "colloidal metallic gold is not bio-inert" ${ }^{180}$. Intraperitoneal injection of $8 \mathrm{mg} / \mathrm{kg} /$ week of 8 to $37 \mathrm{~nm}$ naked gold NPs to mice was lethal within 1 month, whereas 3,5,50, and $100 \mathrm{~nm}$ NPs were not. Toxicity was seen in the liver and spleen, organs that accumulate NPs. The brain was not affected. These results are consistent with the size dependent effects of NPs and their inability to readily enter the brain ${ }^{181}$. Intranasal gold NP was shown to activate microglia in a NP-shapedependent manner. CTAB-coated gold spheres were more toxic than similarly coated nano-rods or nano-urchins, although showing less cell uptake ${ }^{62}$. However, CTAB is toxic and these results may reflect the surfactant equilibrium. Sub-retinal injection of goat IgG-adsorbed gold NPs produced outer retinal degeneration 1 week later in the rabbit ${ }^{182}$. Citrate-capped spherical gold NPs $(\sim 50 \mathrm{~nm})$ injected into the brain of the false dead-head roach (Blaberus discoidalis) were seen in the brain and nerve cord, demonstrating neuronal transport. Decreased locomotion was seen 2 to 6 weeks later. The NPs were protein encapsulated, as is seen with NPs in vivo ${ }^{183}$. These results illustrate the uptake, effects, and opsonization of metal-based NPs. Although it has been suggested gold nanorods might produce an asbestos-like mesothelioma similar to that produced by high-aspect-ratio carbon nanotubes, there are no reports of studies that assessed this. A study of 3 to $60 \mathrm{~nm}$ gold NPs in primary rat brain microvessel endothelial cells showed only moderately decreased cell viability with the small gold NPs at concentrations $\geq 7.8 \mu \mathrm{g} / \mathrm{cm}^{2}$ cell surface area and no change in basal levels of various pro-inflammatory mediators, in cell morphology, or in BBB integrity ${ }^{184}$, demonstrating an exposure level producing little effect. There appears to be only one dose-response assessment of gold NP toxicity to the NS in vivo that defines a lowest 
observable effect level (LOEL) and no observable (observed) effect level (NOEL). It is reviewed in a risk assessment context in ${ }^{2}$.

\section{CONCLUSIONS AND RESEARCH NEEDS}

Knowledge of colloid chemistry can significantly advance the development of surfacemodified NPs and our understanding of NP opsonization in biological milieu. Much work has been done with cells in culture as proof of the concept that novel NPs interact with NS cells. Less work has been done testing those materials in vivo. Given the formidable barriers to NS entry provided by the BBB, BCSFB, and BNB, there is great need to advance the study of these materials in the intact whole animal.

In vitro results with metal-based NPs suggest cause for concern, but in vivo results show very low NP brain entry. Given the very low distribution of NPs into the NS, much work has been done using exposure concentrations and doses that exceed expected acute exposure, although they may model achievable levels after repeated exposure of biologically insoluble NPs. To advance the risk assessment process, lower exposures and multiple doses also need to be studied to determine the NOEL/LOEL of the hazards. Future in vitro NS studies should be designed with exposure conditions relevant to NP concentrations that might be achieved in vivo. The status of the literature on interactions of metal-based NPs with the NS is summed up well by ${ }^{178}$, who referred to gold NPs: "Because many teams began their projects independently, there is a great scatter in experimental design, including particle size and shape, functionalization methods, animal types, particle administration doses and methods and so on. Correspondingly, there is a large scatter of data and conclusions on the levels and kinetics of biodistribution and on toxicity estimates". There is a need for work that employs one or a few model, well-characterized, NPs. Gold would be a good candidate. It should include single and repeated exposure (inhalation and i.v.) to multiple doses and resultant NS biodistribution and effects (perhaps compared to other sites). Parallel work should be conducted in vitro with comparable concentrations as those seen in the NS to determine if there are similar responses, as well as similar persistence, accumulation, and effects from repeated exposure. Because NPs are colloids, it is particularly important that their surface chemistry in the various milieux be understood and related to their behavior and effects. The work should maintain the subjects long enough to assess NP persistence, possible resolution (adaptation or compensation) of shorter-term effects, and any delayed effects. A concern is the potential for toxicity associated with NP accumulation from repeated exposure, which would be predicted with NPs that are too large to be cleared by the kidney, insoluble and therefore retained for a prolonged time, and have demonstrated toxicity after single large-dose exposure, e.g., 50,185 . Other topics that have been minimally addressed (if at all) include 1) adverse effects of metal-based NPs on the choroid plexuses, 2) metal-based NP distribution to the spinal cord or PNS, and 3 ) the relative sensitivity to NPs of measures of disrupted BBB function, such as viability, tight junction integrity, metabolic activity, and immune and inflammatory processes. These warrant study.

The authors have no conflict of interest. 
Disclaimer: This manuscript has been reviewed by the National Health and Environmental Effects Research Laboratory of the U.S. Environmental Protection Agency and approved for publication. Approval does not signify that the contents reflect the views of the Agency, nor does mention of trade names or commercial products constitute endorsement or recommendation for use.

Related Articles:

\begin{tabular}{|l|l|}
\hline \multicolumn{1}{|c|}{ Subtopic } & \multicolumn{1}{c|}{ Article title } \\
\hline $\begin{array}{l}\text { Toxicology of } \\
\text { nanomaterials }\end{array}$ & $\begin{array}{l}\text { Physicochemical Factors that Affect Metal and } \\
\text { Metal Oxide Nanoparticle Passage Across } \\
\text { Epithelial Barriers }\end{array}$ \\
\hline $\begin{array}{l}\text { Toxicology of } \\
\text { nanomaterials }\end{array}$ & $\begin{array}{l}\text { Pharmacokinetics of Nanomaterials: An Overview of } \\
\text { Carbon Nanotubes, Fullerenes and Quantum Dots }\end{array}$ \\
\hline $\begin{array}{l}\text { Toxicology of } \\
\text { nanomaterials }\end{array}$ & $\begin{array}{l}\text { Assessing nanoparticle risk poses prodigious } \\
\text { challenges }\end{array}$ \\
\hline
\end{tabular}




\section{REFERENCES}

1. Riviere JE. Pharmacokinetics of nanomaterials: an overview of carbon nanotubes, fullerenes and quantum dots. Wiley Interdiscip Rev Nanomed Nanobiotechnol 2009, 1:26-34.

2. MacPhail RC, Grulke EA, Yokel RA. Assessing nanoparticle risk poses prodigious challenges. Wiley Interdiscip Rev Nanomed Nanobiotechnol 2012.

3. Weller RO, Djuanda E, Yow H-Y, Carare RO. Lymphatic drainage of the brain and the pathophysiology of neurological disease. Acta Neuropathol 2009, 117:114.

4. Muldoon LL, Varallyay P, Kraemer DF, Kiwic G, Pinkston K, Walker-Rosenfeld $\mathrm{SL}$, Neuwelt EA. Trafficking of superparamagnetic iron oxide particles (Combidex) from brain to lymph nodes in the rat. Neuropathol Appl Neurobiol 2004, 30:70-79.

5. Verkhratsky A, Butt A, Editors. Glial Neurobiology: Wiley; 2007.

6. Azevedo FA, Carvalho LR, Grinberg LT, Farfel JM, Ferretti RE, Leite RE, Jacob Filho W, Lent R, Herculano-Houzel S. Equal numbers of neuronal and nonneuronal cells make the human brain an isometrically scaled-up primate brain. J Comp Neurol 2009, 513:532-541.

7. Sherwood CC, Stimpson CD, Raghanti MA, Wildman DE, Uddin M, Grossman LI, Goodman M, Redmond JC, Bonar CJ, Erwin JM, Hof PR. Evolution of increased glia-neuron ratios in the human frontal cortex. Proc Natl Acad Sci U S A 2006, 103:13606-13611.

8. Abitz M, Nielsen RD, Jones EG, Laursen H, Graem N, Pakkenberg B. Excess of neurons in the human newborn mediodorsal thalamus compared with that of the adult. Cereb Cortex 2007, 17:2573-2578.

9. Kandel E, Schwartz J, Jessell T, Siegelbaum S, Hudspeth AJ. Principles of Neural Science due October, 2012. Vol. 5th.

10. Rippel RA, Seifalian AM. Gold revolution--gold nanoparticles for modern medicine and surgery. J Nanosci Nanotechnol 2011, 11:3740-3748.

11. Eastman J. Colloid stability. In: Cosgrove T, ed. Colloid science - Principles, methods and applications: Blackwell Publishing; 2005, 36-49.

12. Leaver J. Protein adsorption on latex particles. In: Schwarz JA, Contescu Cl, eds. Surfaces of nanoparticles and porous materials. New York: Marcel Dekker; 1999, 743-762.

13. Somasundaran P, Markovic B, Krishnakumar S, Yu X. Colloid systems and interfaces - stability of dispersion through polymer and surfactant adsorption. In: Birdi KS, ed. Handbook of surface and colloid chemistry. Boca Raton: CRC Press; 1997.

14. De TK, A. Maitra A. Particle engineering of drug-loaded nanoparticles and their potential drug-targeting applications. In: Birdi KS, ed. Handbook of surface and colloid chemistry. 2nd ed. Boca Raton: CRC Press; 2002.

15. Pochan DJ, Zhu J, Zhang K, Wooley KL, Miesch C, Emrick T. Multicompartment and multigeometry nanoparticle assembly. Soft Matter 2011, 7:2500-2506.

16. Lee M-Y, Park S-J, Park K, Kim KS, Lee H, Hahn SK. Target-specific gene silencing of layer-by-layer assembled gold-cysteamine/siRNA/PEl/HA nanocomplex. ACS Nano 2011, 5:6138-6147. 
17. Liu Y, Sun J, Han J, He Z. Long-circulating targeted nanoparticles for cancer therapy. Curr Nanosci 2010, 6:347-354.

18. Cho W-S, Cho M-J, Jeong J-Y, Choi M-N, Han B-S, Shin H-S, Hong J, Chung B$\mathrm{H}$, Jeong J-Y, Cho M-H. Size-dependent tissue kinetics of PEG-coated gold nanoparticles. Toxicol Appl Pharmacol 2010, 245:116-123.

19. Derfus AM, Chan WCW, Bhatia SN. Probing the cytotoxicity of semiconductor quantum dots. Nano Letters 2004, 4:11-18.

20. Garza-Ocanas L, Ferrer DA, Burt J, Diaz-Torres LA, Ramirez Cabrera M, Rodriguez VT, Lujan Rangel R, Romanovicz D, Jose-Yacaman M. Biodistribution and long-term fate of silver nanoparticles functionalized with bovine serum albumin in rats. Metallomics 2010, 2:204-210.

21. Deng X, Luan Q, Chen W, Wang Y, Wu M, Zhang H, Jiao Z. Nanosized zinc oxide particles induce neural stem cell apoptosis. Nanotechnology 2009, 20:115101.

22. Lin $\mathrm{CH}$, Chang LW, Chang $\mathrm{H}$, Yang MH, Yang CS, Lai WH, Chang WH, Lin P. The chemical fate of the $\mathrm{Cd} / \mathrm{Se} / \mathrm{Te}$-based quantum dot 705 in the biological system: toxicity implications. Nanotechnology 2009, 20:215101/215101215101/215109.

23. Wankhede M, Bouras A, Kaluzova M, Hadjipanayis CG. Magnetic nanoparticles: an emerging technology for malignant brain tumor imaging and therapy. Expert Rev Clin Pharmacol 2012, 5:173-186.

24. Maier-Hauff K, Rothe R, Scholz R, Gneveckow U, Wust P, Thiesen B, Feussner A, von Deimling A, Waldoefner N, Felix R, Jordan A. Intracranial thermotherapy using magnetic nanoparticles combined with external beam radiotherapy: results of a feasibility study on patients with glioblastoma multiforme. $J$ Neurooncol 2007, 81:53-60.

25. Ghosh S, Ghosh MS, Cai T, Diercks DR, Mills NC, Hynds DL. Alternating magnetic field controlled, multifunctional nano-reservoirs: intracellular uptake and improved biocompatibility. Nanoscale Res Lett 2010, 5:195-204.

26. Celardo I, Traversa E, Ghibelli L. Cerium oxide nanoparticles; a promise for applications in therapy. J Exp Ther Oncol 2011, 9:47-51.

27. Neuwelt EA, Varallyay P, Bago AG, Muldoon LL, Nesbit G, Nixon R. Imaging of iron oxide nanoparticles by MR and light microscopy in patients with malignant brain tumours. Neuropathol Appl Neurobiol 2004, 30:456-471.

28. Neuwelt EA, Varallyay CG, Manninger S, Solymosi D, Haluska M, Hunt MA, Nesbit G, Stevens A, Jerosch-Herold M, Jacobs PM, Hoffman JM. The potential of ferumoxytol nanoparticle magnetic resonance imaging, perfusion, and angiography in central nervous system malignancy: a pilot study. Neurosurgery 2007, 60:601-611; discussion 611-602.

29. Maier-Hauff K, Ulrich F, Nestler D, Niehoff H, Wust P, Thiesen B, Orawa H, Budach $\mathrm{V}$, Jordan A. Efficacy and safety of intratumoral thermotherapy using magnetic iron-oxide nanoparticles combined with external beam radiotherapy on patients with recurrent glioblastoma multiforme. J Neurooncol 2011, 103:317324.

30. Hillyer JF, Albrecht RM. Gastrointestinal persorption and tissue distribution of differently sized colloidal gold nanoparticles. J Pharm Sci 2001, 90:1927-1936. 
31. Monteiro-Riviere NA, Filon FL. Skin In: Fadeel BP, Antonio; Shvedova, Anna A ed. Adverse Effects of Engineered Nanomaterials; 2012, 185-207.

32. Choi HS, Liu W, Misra P, Tanaka E, Zimmer JP, Itty Ipe B, Bawendi MG, Frangioni JV. Renal clearance of quantum dots. Nat Biotechnol 2007, 25:11651170.

33. Ohno K, Pettigrew KD, Rapoport SI. Lower limits of cerebrovascular permeability to nonelectrolytes in the conscious rat. Am J Physiol 1978, 235:H299-H307.

34. Bondy SC. Nanoparticles and colloids as contributing factors in neurodegenerative disease. Int J Environ Res Public Health 2011, 8:2200-2211.

35. Tsai PS, Kaufhold JP, Blinder P, Friedman B, Drew PJ, Karten HJ, Lyden PD, Kleinfeld $\mathrm{D}$. Correlations of neuronal and microvascular densities in murine cortex revealed by direct counting and colocalization of nuclei and vessels. $J$ Neurosci 2009, 29:14553-14570.

36. Vorbrodt AW. Ultracytochemical characterization of anionic sites in the wall of brain capillaries. J Neurocytol 1989, 18:359-368.

37. Georgieva JV, Kalicharan D, Couraud P-O, Romero IA, Weksler B, Hoekstra D, Zuhorn IS. Surface characteristics of nanoparticles determine their intracellular fate in and processing by human blood-brain barrier endothelial cells in vitro. Molecular Therapy 2011, 19:318-325.

38. Tang J, Xiong L, Zhou G, Wang S, Wang J, Liu L, Li J, Yuan F, Lu S, Wan Z, Chou L, Xi T. Silver nanoparticles crossing through and distribution in the bloodbrain barrier in vitro. J Nanosci Nanotechnol 2010, 10:6313-6317.

39. Dan M, Tseng MT, Wu P, Unrine JM, Grulke EA, Yokel RA. Brain microvascular endothelial cell association and distribution of a $5 \mathrm{~nm}$ ceria engineered nanomateria. Int J Nanomed 2012, 7:4023-4036.

40. Rapoport SI. Advances in osmotic opening of the blood-brain barrier to enhance CNS chemotherapy. Expert Opin Invest Drugs 2001, 10:1809-1818.

41. Hynynen K, McDannold N, Vykhodtseva N, Raymond S, Weissleder R, Jolesz FA, Sheikov N. Focal disruption of the blood-brain barrier due to $260-\mathrm{kHz}$ ultrasound bursts: a method for molecular imaging and targeted drug delivery. $J$ Neurosurg 2006, 105:445-454.

42. Liu H-L, Hua M-Y, Yang H-W, Huang C-Y, Chu P-C, Wu J-S, Tseng IC, Wang J$\mathrm{J}$, Yen T-C, Chen P-Y, Wei K-C. Magnetic resonance monitoring of focused ultrasound/magnetic nanoparticle targeting delivery of therapeutic agents to the brain. PNAS USA 2010, 107:15205-15210, S15205/15201-S15205/15207.

43. Takeda K, Suzuki K-i, Ishihara A, Kubo-Irie M, Fujimoto R, Tabata M, Oshio S, Nihei $Y$, Ihara T, Sugamata M. Nanoparticles transferred from pregnant mice to their offspring can damage the genital and cranial nerve systems. J Health Sci 2009, 55:95-102.

44. Hunter DD, Undem BJ. Identification and substance P content of vagal afferent neurons innervating the epithelium of the guinea pig trachea. Am J Respir Crit Care Med 1999, 159:1943-1948.

45. Estevanato L, Cintra D, Baldini N, Portilho F, Barbosa L, Martins O, Lacava B, Miranda-Vilela AL, Tedesco AC, Bao S, Morais PC, Lacava ZG. Preliminary biocompatibility investigation of magnetic albumin nanosphere designed as a potential versatile drug delivery system. Int J Nanomedicine 2011, 6:1709-1717. 
46. Cambianica I, Bossi M, Gasco P, Gonzalez W, Idee JM, Miserocchi G, Rigolio R, Chanana M, Morjan I, Wang D, Sancini G. Targeting cells with MR imaging probes: Cellular interaction and intracellular magnetic iron oxide nanoparticles uptake in brain capillary endothelial and choroidal plexus epithelial cells. AIP Conf Proc 2010, 1275:145-149.

47. Wittendorp-Rechenmann E, Namer IJ, Steibel J, Lam DC, Pouliquen D. Superparamagnetic nanoparticles containing liposomes as potential specific contrast agent for brain MR imaging: initial feasibility study by a combined approach with ${ }^{59} \mathrm{Fe}$-activated track-autoradiography. J Trace Microprobe Tech 1998, 16:523-534.

48. Nau R, Soergel F, Eiffert H. Penetration of drugs through the blood-cerebrospinal fluid/blood-brain barrier for treatment of central nervous system infections. Clin Microbiol Rev 2010, 23:858-883.

49. Felgenhauer K. Protein filtration and secretion at human body fluid barriers. Pfluegers Arch 1980, 384:9-17.

50. Yokel RA, Au TC, MacPhail R, Hardas SS, Butterfield DA, Sultana R, Tseng MT, Dan M, Florence RL, Unrine JM, Graham UM, Wu P, Grulke EA. Distribution, elimination and biopersistence to 90 days of a systemically-introduced $30 \mathrm{~nm}$ ceria engineered nanomaterial in rats. Toxicol Sci 2012, 127:256-268.

51. de Lorenzo AJD. The olfactory neuron and the blood-brain barrier. In: Wolstenholme G, Knight J, eds. Taste and smell in vertebrates. London: Churchhill; 1970, 151-176.

52. Oberdörster G, Sharp Z, Atudorei V, Elder A, Gelein R, Kreyling W, Cox C. Translocation of inhaled ultrafine particles to the brain. Inhalation Toxicology 2004, 16:437-445.

53. Elder A, Gelein R, Silva V, Feikert T, Opanashuk L, Carter J, Potter R, Maynard A, Ito $Y$, Finkelstein J, Oberdörster G. Translocation of inhaled ultrafine manganese oxide particles to the central nervous system. Environ Health Perspect 2006, 114:1172-1178.

54. Gao X, Chen J, Chen J, Wu B, Chen H, Jiang X. Quantum dots bearing lectinfunctionalized nanoparticles as a platform for in vivo brain imaging. Bioconjugate Chem 2008, 19:2189-2195.

55. Yu LE, Yung L-YL, Ong C-N, Tan Y-L, Balasubramaniam KS, Hartono D, Shui G, Wenk MR, Ong W-Y. Translocation and effects of gold nanoparticles after inhalation exposure in rats. Nanotoxicology 2007, 1:235-242.

56. Sung JH, Ji JH, Park JD, Song MY, Song KS, Ryu HR, Yoon JU, Jeon KS, Jeong J, Han BS, Chung YH, Chang HK, Lee JH, Kim DW, Kelman BJ, Yu IJ. Subchronic inhalation toxicity of gold nanoparticles. Part Fibre Toxicol 2011, 8:16.

57. Wang J, Chen C, Liu Y, Jiao F, Li W, Lao F, Li Y, Li B, Ge C, Zhou G, Gao Y, Zhao Y, Chai Z. Potential neurological lesion after nasal instillation of $\mathrm{TiO}_{2}$ nanoparticles in the anatase and rutile crystal phases. Toxicol Lett 2008, 183:7280.

58. Wang J, Liu Y, Jiao F, Lao F, Li W, Gu Y, Li Y, Ge C, Zhou G, Li B, Zhao Y, Chai $Z$, Chen $\mathrm{C}$. Time-dependent translocation and potential impairment on central nervous system by intranasally instilled $\mathrm{TiO}_{2}$ nanoparticles. Toxicology 2008 , 254:82-90. 
59. Wang $B$, Feng $W$, Zhu $M$, Wang $Y$, Wang $M$, Gu $Y$, Ouyang $H$, Wang $H$, Li M, Zhao $\mathrm{Y}$, Chai Z, Wang $\mathrm{H}$. Neurotoxicity of low-dose repeatedly intranasal instillation of nano- and submicron-sized ferric oxide particles in mice. J Nanopart Res 2009, 11:41-53.

60. Wang Y, Wang B, Zhu MT, Li M, Wang HJ, Wang M, Ouyang H, Chai ZF, Feng WY, Zhao YL. Microglial activation, recruitment and phagocytosis as linked phenomena in ferric oxide nanoparticle exposure. Toxicol Lett 2011, 205:26-37.

61. Lalancette-Hebert M, Moquin A, Choi AO, Kriz J, Maysinger D. Lipopolysaccharide-QD micelles induce marked induction of TLR2 and lipid droplet accumulation in olfactory bulb microglia. Mol Pharmaceutics 2010, 7:1183-1194.

62. Hutter E, Boridy S, Labrecque S, Lalancette-Hebert M, Kriz J, Winnik FM, Maysinger D. Microglial response to gold nanoparticles. ACS Nano 2010, 4:2595-2606.

63. Liu Y, Guan W, Ren G, Yang Z. The possible mechanism of silver nanoparticle impact on hippocampal synaptic plasticity and spatial cognition in rats. Toxicol Lett 2012, 209:227-231.

64. Garcia GJM, Kimbell JS. Deposition of inhaled nanoparticles in the rat nasal passages: dose to the olfactory region. Inhal Toxicol 2009, 21:1165-1175.

65. Oberdörster G, Oberdörster E, Oberdörster J. Nanotoxicology: an emerging discipline evolving from studies of ultrafine particles. Environ Health Perspect 2005, 113:823-839.

66. Czerniawska A. Experimental investigations on the penetration of ${ }^{198} \mathrm{Au}$ from nasal mucous membrane into cerebrospinal fluid. Acta Otolaryngologica 1970, 70:58-61.

67. Hadjipanayis CG, Machaidze R, Kaluzova M, Wang L, Schuette AJ, Chen H, Wu $\mathrm{X}$, Mao H. EGFRvIll antibody-conjugated iron oxide nanoparticles for magnetic resonance imaging-guided convection-enhanced delivery and targeted therapy of glioblastoma. Cancer Res 2010, 70:6303-6312.

68. Corem-Salkmon E, Ram Z, Daniels D, Perlstein B, Last D, Salomon S, Tamar G, Shneor R, Guez D, Margel S, Mardor Y. Convection-enhanced delivery of methotrexate-loaded maghemite nanoparticles. Int J Nanomed 2011, 6:15951602.

69. Daneshvar H, Nelms J, Muhammad O, Jackson H, Tkach J, Davros W, Peterson T, Vogelbaum MA, Bruchez MP, Toms SA. Imaging characteristics of zinc sulfide shell, cadmium telluride core quantum dots. Nanomedicine (Lond) 2008, 3:21-29.

70. Conner SD, Schmid SL. Regulated portals of entry into the cell. Nature (London, U. K.) 2003, 422:37-44.

71. $\mathrm{Xu} \mathrm{J,} \mathrm{Ling} \mathrm{EA.} \mathrm{Studies} \mathrm{of} \mathrm{the} \mathrm{ultrastructure} \mathrm{and} \mathrm{permeability} \mathrm{of} \mathrm{the} \mathrm{blood-brain}$ barrier in the developing corpus callosum in postnatal rat brain using electron dense tracers. J Anat 1994, 184 ( Pt 2):227-237.

72. Yokel RA. Blood-brain barrier flux of aluminum, manganese, iron and other metals suspected to contribute to metal-induced neurodegeneration. $J$ Alzheimer's Dis 2006, 10:223-253.

73. Kato S, Itoh K, Yaoi T, Tozawa T, Yoshikawa Y, Yasui H, Kanamura N, Hoshino A, Manabe N, Yamamoto K, Fushiki S. Organ distribution of quantum dots after 
intraperitoneal administration, with special reference to area-specific distribution in the brain. Nanotechnology 2010, 21:335103/335101-335103/335107.

74. Chithrani BD, Chan WC. Elucidating the mechanism of cellular uptake and removal of protein-coated gold nanoparticles of different sizes and shapes. Nano Lett 2007, 7:1542-1550.

75. AshaRani PV, Hande MP, Valiyaveettil S. Anti-proliferative activity of silver nanoparticles. BMC Cell Biol 2009, 10:65.

76. dos Santos T, Varela J, Lynch I, Salvati A, Dawson KA. Quantitative assessment of the comparative nanoparticle-uptake efficiency of a range of cell lines. Small 2011, 7:3341-3349.

77. Shi X, von dem Bussche A, Hurt RH, Kane AB, Gao H. Cell entry of onedimensional nanomaterials occurs by tip recognition and rotation. Nat Nanotechnol 2011, 6:714-719.

78. Kim JH, Kim JH, Kim KW, Kim MH, Yu YS. Intravenously administered gold nanoparticles pass through the blood-retinal barrier depending on the particle size, and induce no retinal toxicity. Nanotechnology 2009, 20:505101.

79. Jo DH, Lee TG, Kim JH. Nanotechnology and nanotoxicology in retinopathy. Int J Mol Sci 2011, 12:8288-8301.

80. Chen Y-S, Hung Y-C, Lin L-W, Liau I, Hong M-Y, Huang GS. Size-dependent impairment of cognition in mice caused by the injection of gold nanoparticles. Nanotechnology 2010, 21:485102/485101-485102/485109.

81. Schleh C, Semmler-Behnke M, Lipka J, Wenk A, Hirn S, Schaeffler M, Schmid G, Simon U, Kreyling WG. Size and surface charge of gold nanoparticles determine absorption across intestinal barriers and accumulation in secondary target organs after oral administration. Nanotoxicology 2012, 6:36-46.

82. Hirn S, Semmler-Behnke M, Schleh C, Wenk A, Lipka J, Schaffler M, Takenaka S, Moller W, Schmid G, Simon U, Kreyling WG. Particle size-dependent and surface charge-dependent biodistribution of gold nanoparticles after intravenous administration. Eur J Pharm Biopharm 2011, 77:407-416.

83. Nel AE, Madler L, Velegol D, Xia T, Hoek EM, Somasundaran P, Klaessig F, Castranova V, Thompson M. Understanding biophysicochemical interactions at the nano-bio interface. Nat Mater 2009, 8:543-557.

84. Auffan M, Rose J, Bottero J-Y, Lowry GV, Jolivet J-P, Wiesner MR. Towards a definition of inorganic nanoparticles from an environmental, health and safety perspective. Nature Nanotechnology 2009, 4:634-641.

85. Lacerda SH, Park JJ, Meuse C, Pristinski D, Becker ML, Karim A, Douglas JF. Interaction of gold nanoparticles with common human blood proteins. ACS Nano 2010, 4:365-379.

86. Fenart L, Casanova A, Dehouck B, Duhem C, Slupek S, Cecchelli R, Betbeder D. Evaluation of effect of charge and lipid coating on ability of $60-\mathrm{nm}$ nanoparticles to cross an in vitro model of the blood-brain barrier. J Pharmacol Exp Ther 1999, 291:1017-1022.

87. Jallouli Y, Paillard A, Chang J, Sevin E, Betbeder D. Influence of surface charge and inner composition of porous nanoparticles to cross blood-brain barrier in vitro. Int J Pharm 2007, 344:103-109. 
88. Lockman PR, Koziara JM, Mumper RJ, Allen DD. Nanoparticle surface charges alter blood-brain barrier integrity and permeability. J Drug Targeting 2004, 12:635-641.

89. Reddy LH, Sharma RK, Chuttani K, Mishra AK, Murthy RR. Etoposideincorporated tripalmitin nanoparticles with different surface charge: Formulation, characterization, radiolabeling, and biodistribution studies. AAPS J. 2004, 6:5564.

90. Guerrero S, Araya E, Fiedler JL, Arias JI, Adura C, Albericio F, Giralt E, Arias JL, Fernandez MS, Kogan MJ. Improving the brain delivery of gold nanoparticles by conjugation with an amphipathic peptide. Nanomedicine (London, U. K.) 2010, 5:897-913.

91. Borm PJA, Robbins D, Haubold S, Kuhlbusch T, Fissan H, Donaldson KS, Roel, Stone V, Kreyling W, Lademann J, Krutmann J, Warheit D, Oberdörster E. The potential risks of nanomaterials: A review carried out for ECETOC. Particle Fibre Toxicol 2006, 3:35 pages.

92. Walczyk D, Bombelli FB, Monopoli MP, Lynch I, Dawson KA. What the cell "sees" in bionanoscience. J Am Chem Soc 2010, 132:5761-5768.

93. Monopoli MP, Walczyk D, Campbell A, Elia G, Lynch I, Bombelli FB, Dawson KA. Physical-chemical aspects of protein corona: relevance to in vitro and in vivo biological impacts of nanoparticles. J Am Chem Soc 2011, 133:2525-2534.

94. Dutta D, Sundaram SK, Teeguarden JG, Riley BJ, Fifield LS, Jacobs JM, Addleman SR, Kaysen GA, Moudgil BM, Weber TJ. Adsorbed proteins influence the biological activity and molecular targeting of nanomaterials. Toxicol Sci 2007, 100:303-315.

95. Horie M, Nishio K, Fujita K, Endoh S, Miyauchi A, Saito Y, Iwahashi H, Yamamoto K, Murayama H, Nakano H, Nanashima N, Niki E, Yoshida Y. Protein adsorption of ultrafine metal oxide and its Influence on cytotoxicity toward cultured cells. Chem Res Toxicol 2009, 22:543-553.

96. Kreuter J. Influence of the surface properties on nanoparticle-mediated transport of drugs to the brain. J Nanosci Nanotechnol 2004, 4:484-488.

97. Brown DM, Wilson MR, MacNee W, Stone V, Donaldson K. Size-dependent proinflammatory effects of ultrafine polystyrene particles: a role for surface area and oxidative stress in the enhanced activity of ultrafines. Toxicol Appl Pharmacol 2001, 175:191-199.

98. Hagens WI, Oomen AG, de Jong WH, Cassee FR, Sips AJ. What do we (need to) know about the kinetic properties of nanoparticles in the body? Regul Toxicol Pharmacol 2007, 49:217-229.

99. Foster KA, Yazdanian M, Audus KL. Microparticulate uptake mechanisms of invitro cell culture models of the respiratory epithelium. J Pharm Pharmacol 2001, 53:57-66.

100. Deng ZJ, Mortimer G, Schiller T, Musumeci A, Martin D, Minchin RF. Differential plasma protein binding to metal oxide nanoparticles. Nanotechnology 2009, 20:455101/455101-455101/455109.

101. Georgieva JV, Kalicharan D, Couraud PO, Romero IA, Weksler B, Hoekstra D, Zuhorn IS. Surface characteristics of nanoparticles determine their intracellular fate in and processing by human blood-brain barrier endothelial cells in vitro. Mol Ther 2011, 19:318-325. 
102. Phenrat T, Long TC, Lowry GV, Veronesi B. Partial oxidation ("aging") and surface modification decrease the toxicity of nanosized zerovalent iron. Environ Sci Technol 2009, 43:195-200.

103. Lovric J, Bazzi HS, Cuie Y, Fortin GR, Winnik FM, Maysinger D. Differences in subcellular distribution and toxicity of green and red emitting CdTe quantum dots. J Molecular Med 2005, 83:377-385.

104. Maysinger D, Behrendt M, Lalancette-Hebert M, Kriz J. Real-time imaging of astrocyte response to quantum dots: in vivo screening model system for biocompatibility of nanoparticles. Nano Lett 2007, 7:2513-2520.

105. Long TC, Saleh N, Tilton RD, Lowry GV, Veronesi B. Titanium dioxide (P25) produces reactive oxygen species in immortalized brain microglia (BV2): Implications for nanoparticle neurotoxicity. Environ Sci Technol 2006, 40:43464352.

106. Haase A, Rott S, Mantion A, Graf P, Plendl J, Thunemann AF, Meier WP, Taubert A, Luch A, Reiser G. Effects of silver nanoparticles on primary mixed neural cell cultures: uptake, oxidative stress and acute calcium responses. Toxicol Sci 2012, 126:457-468.

107. Sharma HS, Sharma A. Nanoparticles aggravate heat stress induced cognitive deficits, blood-brain barrier disruption, edema formation and brain pathology. Prog Brain Res 2007, 162:245-273.

108. Sharma HS, Ali SF, Hussain SM, Schlager JJ, Sharma A. Influence of engineered nanoparticles from metals on the blood-brain barrier permeability, cerebral blood flow, brain edema and neurotoxicity. An experimental study in the rat and mice using biochemical and morphological approaches. $J$ Nanosci Nanotechnol 2009, 9:5055-5072.

109. Sharma HS, Ali SF, Tian ZR, Hussain SM, Schlager JJ, Sjoquist PO, Sharma A, Muresanu DF. Chronic treatment with nanoparticles exacerbate hyperthermia induced blood-brain barrier breakdown, cognitive dysfunction and brain pathology in the rat. Neuroprotective effects of nanowired-antioxidant compound H-290/51. J Nanosci Nanotechnol 2009, 9:5073-5090.

110. Mejias R, Perez-Yague S, Roca AG, Perez N, Villanueva A, Canete M, Manes S, Ruiz-Cabello J, Benito M, Labarta A, Batlle X, Veintemillas-Verdaguer S, Morales MP, Barber DF, Serna CJ. Liver and brain imaging through dimercaptosuccinic acid-coated iron oxide nanoparticles. Nanomedicine (Lond) 2010, 5:397-408.

111. Kim JS, Yoon TJ, Yu KN, Kim BG, Park SJ, Kim HW, Lee KH, Park SB, Lee JK, $\mathrm{Cho} \mathrm{MH}$. Toxicity and tissue distribution of magnetic nanoparticles in mice. Toxicol Sci 2006, 89:338-347.

112. Yokel RA, Florence RL, Unrine JM, Tseng MT, Graham UM, Wu P, Grulke EA, Sultana R, Hardas SS, Butterfield DA. Biodistribution and oxidative stress effects of a systemically-introduced commercial ceria engineered nanomaterial. Nanotoxicology 2009, 3:234-248.

113. Hardas SS, Butterfield DA, Sultana R, Tseng MT, Dan M, Florence RL, Unrine JM, Graham UM, Wu P, Grulke EA, Yokel RA. Brain distribution and toxicological evaluation of a systemically delivered engineered nanoscale ceria. Toxicol Sci 2010, 116:562-576. 
114. Chen L, Yokel RA, Hennig B, Toborek M. Manufactured aluminum oxide nanoparticles decrease expression of tight junction proteins in brain vasculature. J Neuroimmune Pharmacol 2008, 3:286-295.

115. Brun E, Carriere M, Mabondzo A. In vitro evidence of dysregulation of bloodbrain barrier function after acute and repeated/long-term exposure to $\mathrm{TiO}_{2}$ nanoparticles. Biomaterials 2012, 33:886-896.

116. Trickler WJ, Lantz SM, Murdock RC, Schrand AM, Robinson BL, Newport GD, Schlager JJ, Oldenburg SJ, Paule MG, Slikker W, Jr., Hussain SM, Ali SF. Silver nanoparticle induced blood-brain barrier inflammation and increased permeability in primary rat brain microvessel endothelial cells. Toxicol Sci 2010, 118:160-170.

117. Trickler WJ, Lantz SM, Schrand AM, Robinson BL, Newport GD, Schlager JJ, Paule MG, Slikker W, Biris AS, Hussain SM, Ali SF. Effects of copper nanoparticles on rat cerebral microvessel endothelial cells. Nanomedicine (Lond) 2012, 7:835-846.

118. Wang J, Zhou G, Chen C, Yu H, Wang T, Ma Y, Jia G, Gao Y, Li B, Sun J, Li Y, Jiao F, Zhao Y, Chai Z. Acute toxicity and biodistribution of different sized titanium dioxide particles in mice after oral administration. Toxicol Lett 2007, 168:176-185.

119. Ma L, Liu J, Li N, Wang J, Duan Y, Yan J, Liu H, Wang H, Hong F. Oxidative stress in the brain of mice caused by translocated nanoparticulate $\mathrm{TiO}_{2}$ delivered to the abdominal cavity. Biomaterials 2010, 31:99-105.

120. Hu R, Gong X, Duan Y, Li N, Che Y, Cui Y, Zhou M, Liu C, Wang H, Hong F. Neurotoxicological effects and the impairment of spatial recognition memory in mice caused by exposure to $\mathrm{TiO}_{2}$ nanoparticles. Biomaterials 2010, 31:80438050.

121. Shin JA, Lee EJ, Seo SM, Kim HS, Kang JL, Park EM. Nanosized titanium dioxide enhanced inflammatory responses in the septic brain of mouse. Neuroscience (Amsterdam, Neth.) 2010, 165:445-454.

122. Lee H-Y, Choi Y-J, Jung E-J, Yin H-Q, Kwon J-T, Kim J-E, Im H-T, Cho M-H, Kim $\mathrm{J}-\mathrm{H}, \mathrm{Kim} \mathrm{H}-\mathrm{Y}$, Lee B-H. Genomics-based screening of differentially expressed genes in the brains of mice exposed to silver nanoparticles via inhalation. $J$ Nanopart Res 2010, 12:1567-1578.

123. Campbell A, Oldham M, Becaria A, Bondy SC, Meacher D, Sioutas C, Misra C, Mendez LB, Kleinman M. Particulate matter in polluted air may increase biomarkers of inflammation in mouse brain. Neurotoxicology 2005, 26:133-140.

124. Utell MJ, Frampton MW, Zareba W, Devlin RB, Cascio WE. Cardiovascular effects associated with air pollution: potential mechanisms and methods of testing. Inhal Toxicol 2002, 14:1231-1247.

125. Bhabra G, Sood A, Fisher B, Cartwright L, Saunders M, Evans WH, Surprenant A, Lopez-Castejon G, Mann S, Davis SA, Hails LA, Ingham E, Verkade P, Lane $\mathrm{J}$, Heesom K, Newson R, Case CP. Nanoparticles can cause DNA damage across a cellular barrier. Nature Nanotechnology 2009, 4:876-883.

126. Xu R, Ma J, Sun X, Chen Z, Jiang X, Guo Z, Huang L, Li Y, Wang M, Wang C, Liu J, Fan X, Gu J, Chen X, Zhang Y, Gu N. Ag nanoparticles sensitize IRinduced killing of cancer cells. Cell Res 2009, 19:1031-1034. 
127. Pompa PP, Vecchio G, Galeone A, Brunetti V, Maiorano G, Sabella S, Cingolani R. Physical assessment of toxicology at nanoscale: nano dose-metrics and toxicity factor. Nanoscale 2011, 3:2889-2897.

128. Vecchio G, Galeone A, Brunetti V, Maiorano G, Sabella S, Cingolani R, Pompa PP. Concentration-dependent, size-independent toxicity of citrate capped AuNPs in Drosophila melanogaster. PLoS One 2012, 7:e29980.

129. Wang H-J, Yang L, Yang H-Y, Wang K, Yao W-G, Jiang K, Huang X-L, Zheng Z. Antineoplastic activities of protein-conjugated silver sulfide nano-crystals with different shapes. J Inorg Biochem 2010, 104:87-91.

130. Tarantola M, Pietuch A, Schneider D, Rother J, Sunnick E, Rosman C, Pierrat S, Sonnichsen C, Wegener J, Janshoff A. Toxicity of gold-nanoparticles: synergistic effects of shape and surface functionalization on micromotility of epithelial cells. Nanotoxicology 2011, 5:254-268.

131. Mahto SK, Yoon TH, Rhee SW. Cytotoxic effects of surface-modified quantum dots on neuron-like PC12 cells cultured inside microfluidic devices. BioChip J 2010, 4:82-88.

132. Soenen SJH, Himmelreich U, Nuytten N, Pisanic IITR, Ferrari A, De CM. Intracellular nanoparticle coating stability determines nanoparticle diagnostics efficacy and cell functionality. Small 2010, 6:2136-2145.

133. Soenen SJH, Himmelreich U, Nuytten N, De CM. Cytotoxic effects of iron oxide nanoparticles and implications for safety in cell labeling. Biomaterials 2010, 32:195-205.

134. Rivet CJ, Yuan Y, Borca-Tasciuc D-A, Gilbert RJ. Altering iron oxide nanoparticle surface properties induce cortical neuron cytotoxicity. Che. Res Toxicol 2012, 25:153-161.

135. Bolis V, Busco C, Ciarletta M, Distasi C, Erriquez J, Fenoglio I, Livraghi S, Morel $\mathrm{S}$. Hydrophilic/hydrophobic features of $\mathrm{TiO}_{2}$ nanoparticles as a function of crystal phase, surface area and coating, in relation to their potential toxicity in peripheral nervous system. J Colloid Interface Sci 2012, 369:28-39.

136. Cui B, Wu C, Chen L, Ramirez A, Bearer EL, Li W-P, Mobley WC, Chu S. One at a time, live tracking of NGF axonal transport using quantum dots. PNAS USA 2007, 104:13666-13671.

137. Jain MP, Choi AO, Neibert KD, Maysinger D. Probing and preventing quantum dot-induced cytotoxicity with multimodal alpha-lipoic acid in multiple dimensions of the peripheral nervous system. Nanomedicine (Lond) 2009, 4:277-290.

138. Jaiswal AR, Lu S, Pfau J, Wong YYW, Bhushan A, Leung SW, Daniels CK, Lai JCK. Effects of silicon dioxide nanoparticles on peripheral nervous system neural cell models. In: Nanotech Conference \& Expo 2011: An Interdisciplinary Integrative Forum on Nanotechnology, Biotechnology and Microtechnology. Boston, MA: CRC Press; 2011.

139. Oszlanczi G, Papp A, Szaboo A, Nagymajtenyi L, Sapi A, Konya Z, Paulik E, Vezer T. Nervous system effects in rats on subacute exposure by lead-containing nanoparticles via the airways. Inhalation Toxicol 2011, 23:173-181.

140. Lu S, Jaiswal AR, Wong YYW, Bhushan A, Leung SW, Daniels CK, Lai JCK. Differential cytotoxic effects of titanium oxide nanoparticles on peripheral nervous system neural cells. In: Nanotech Conference \& Expo 2011: An Interdisciplinary 
Integrative Forum on Nanotechnology, Biotechnology and Microtechnology. Boston, MA: CRC Press; 2011.

141. Menon PK, Muresanu DF, Sharma A, Moessler H, Sharma HS. Cerebrolysin, a mixture of neurotrophic factors induces marked neuroprotection in spinal cord injury following intoxication of engineered nanoparticles from metals. CNS Neurol Disord: Drug Targets 2012, 11:40-49.

142. Sharma HS, Sharma A. Nanowired drug delivery for neuroprotection in central nervous system injuries: modulation by environmental temperature, intoxication of nanoparticles, and comorbidity factors. Wiley Interdiscip Rev Nanomed Nanobiotechnol 2012, 4:184-203.

143. Lin Y-L, Jen J-C, Hsu S-h, Chiu I-M. Sciatic nerve repair by microgrooved nerve conduits made of chitosan-gold nanocomposites. Surg Neurol 2008, 70 Suppl 1:S1:9-18.

144. Das M, Patil S, Bhargava N, Kang JF, Riedel LM, Seal S, Hickman JJ. Autocatalytic ceria nanoparticles offer neuroprotection to adult rat spinal cord neurons. Biomaterials 2007, 28:1918-1925.

145. Cannon JR, Greenamyre JT. The role of environmental exposures in neurodegeneration and neurodegenerative diseases. Toxicol Sci 2011, 124:225250.

146. Geppert M, Hohnholt MC, Thiel K, Nuernberger S, Grunwald I, Rezwan K, Dringen R. Uptake of dimercaptosuccinate-coated magnetic iron oxide nanoparticles by cultured brain astrocytes. Nanotechnology 2011, 22:145101/145101-145101/145110.

147. Yiu HHP, Pickard MR, Olariu Cl, Williams SR, Chari DM, Rosseinsky MJ. $\mathrm{Fe}_{3} \mathrm{O}_{4-}$ PEI-RITC magnetic nanoparticles with imaging and gene transfer capability: Development of a tool for neural cell transplantation therapies. Pharm Res 2012, 29:1328-1343.

148. Long TC, Tajuba J, Sama P, Saleh N, Swartz C, Parker J, Hester S, Lowry GV, Veronesi B. Nanosize titanium dioxide stimulates reactive oxygen species in brain microglia and damages neurons in vitro. Environ Health Perspect 2007, 115:1631-1637.

149. Przybytkowski E, Behrendt M, Dubois D, Maysinger D. Nanoparticles can induce changes in the intracellular metabolism of lipids without compromising cellular viability. FEBS J 2009, 276:6204-6217.

150. Chan WH, Shiao NH, Lu PZ. CdSe quantum dots induce apoptosis in human neuroblastoma cells via mitochondrial-dependent pathways and inhibition of survival signals. Toxicol Lett 2006, 167:191-200.

151. Choi AO, Cho SJ, Desbarats J, Lovric J, Maysinger D. Quantum dot-induced cell death involves Fas upregulation and lipid peroxidation in human neuroblastoma cells. J Nanobiotechnology 2007, 5:1.

152. Tang M, Xing T, Zeng J, Wang H, Li C, Yin S, Yan D, Deng H, Liu J, Wang M, Chen J, Ruan D-Y. Unmodified CdSe quantum dots induce elevation of cytoplasmic calcium levels and impairment of functional properties of sodium channels in rat primary cultured hippocampal neurons. Environ Health Perspect 2008, 116:915-922.

153. Lai JCK, Lai MB, Jandhyam S, Dukhande VV, Bhushan A, Daniels CK, Leung SW. Exposure to titanium dioxide and other metallic oxide nanoparticles induces 
cytotoxicity on human neural cells and fibroblasts. Int J Nanomed 2008, 3:533545.

154. Pinkernelle J, Calatayud P, Goya GF, Fansa H, Keilhoff G. Magnetic nanoparticles in primary neural cell cultures are mainly taken up by microglia. BMC Neurosci 2012, 13:32.

155. Zeng G, Wang G, Guan F, Chang K, Jiao H, Gao W, Xi S, Yang B. Human amniotic membrane-derived mesenchymal stem cells labeled with superparamagnetic iron oxide nanoparticles: the effect on neuron-like differentiation in vitro. Mol Cell Biochem 2011, 357:331-341.

156. Asharani PV, Wu YL, Gong Z, Valiyaveettil S. Toxicity of silver nanoparticles in zebrafish models. Nanotechnology 2008, 19:255102/255101-255102/255108.

157. Jovanovic B, Ji T, Palic D. Gene expression of zebrafish embryos exposed to titanium dioxide nanoparticles and hydroxylated fullerenes. Ecotoxicol Environ Saf 2011, 74:1518-1525.

158. Chen J, Dong X, Xin Y, Zhao M. Effects of titanium dioxide nano-particles on growth and some histological parameters of zebrafish (Danio rerio) after a longterm exposure. Aquat Toxicol 2011, 101:493-499.

159. Palaniappan PR, Pramod KS. The effect of titanium dioxide on the biochemical constituents of the brain of Zebrafish (Danio rerio): An FT-IR study. Spectrochim Acta, Part A 2011, 79:206-212.

160. Truong L, Tilton S, Zaikov T, Richman E, Waters KH, JE, Tanguay R. Surface functionalities of gold nanoparticles impact embryonic gene expression responses. Nanotoxicology 2012, Jan 20. [Epub ahead of print].

161. Chen T-H, Lin C-Y, Tseng M-C. Behavioral effects of titanium dioxide nanoparticles on larval zebrafish (Danio rerio). Mar Pollut Bull 2011, 63:303-308.

162. Zhang H, He X, Zhang Z, Zhang P, Li Y, Ma Y, Kuang Y, Zhao Y, Chai Z. Nano$\mathrm{CeO}_{2}$ exhibits adverse effects at environmental relevant concentrations. Environ Sci Technol 2011, 45:3725-3730.

163. Ma H, Bertsch PM, Glenn TC, Kabengi NJ, Williams PL. Toxicity of manufactured zinc oxide nanoparticles in the nematode Caenorhabditis elegans.

EnvironToxicol Chem 2009, 28:1324-1330.

164. Choi $\mathrm{CH}$, Alabi CA, Webster $\mathrm{P}$, Davis ME. Mechanism of active targeting in solid tumors with transferrin-containing gold nanoparticles. PNAS USA 2010, 107:1235-1240.

165. Kim YH, Jeon J, Hong SH, Rhim WK, Lee YS, Youn H, Chung JK, Lee MC, Lee DS, Kang KW, Nam JM. Tumor targeting and imaging using cyclic RGDPEGylated gold nanoparticle probes with directly conjugated iodine-125. Small 2011, 7:2052-2060.

166. Cheng Y, Meyers JD, Agnes RS, Doane TL, Kenney ME, Broome A-M, Burda C, Basilion JP. Addressing brain tumors with targeted gold nanoparticles: A new gold standard for hydrophobic drug delivery? Small 2011, 7:2301-2306.

167. Dhar S, Reddy EM, Prabhune A, Pokharkar V, Shiras A, Prasad BL. Cytotoxicity of sophorolipid-gellan gum-gold nanoparticle conjugates and their doxorubicin loaded derivatives towards human glioma and human glioma stem cell lines. Nanoscale 2011, 3:575-580. 
168. Ip S, MacLaughlin CM, Gunari N, Walker GC. Phospholipid membrane encapsulation of nanoparticles for surface-enhanced Raman scattering. Langmuir 2011, 27:7024-7033.

169. Lasagna-Reeves C, Gonzalez-Romero D, Barria MA, Olmedo I, Clos A, Sadagopa Ramanujam VM, Urayama A, Vergara L, Kogan MJ, Soto C. Bioaccumulation and toxicity of gold nanoparticles after repeated administration in mice. Biochem Biophys Res Commun 2010, 393:649-655.

170. De Jong WH, Hagens WI, Krystek P, Burger MC, Sips AJ, Geertsma RE. Particle size-dependent organ distribution of gold nanoparticles after intravenous administration. Biomaterials 2008, 29:1912-1919.

171. Terentyuk GS, Maslyakova GN, Suleymanova LV, Khlebtsov BN, Kogan BY, Akchurin GG, Shantrocha AV, Maksimova IL, Khlebtsov NG, Tuchin VV. Circulation and distribution of gold nanoparticles and induced alterations of tissue morphology at intravenous particle delivery. J Biophotonics 2009, 2:292-302.

172. Cho WS, Cho M, Jeong J, Choi M, Cho HY, Han BS, Kim SH, Kim HO, Lim YT, Chung $\mathrm{BH}$. Acute toxicity and pharmacokinetics of $13 \mathrm{~nm}$-sized PEG-coated gold nanoparticles. Toxicol Appl Pharmacol 2009, 236:16-24.

173. dos Santos Silva I, Malveiro F, Jones ME, Swerdlow AJ. Mortality after radiological investigation with radioactive Thorotrast: a follow-up study of up to fifty years in Portugal. Radiat Res 2003, 159:521-534.

174. Fabian E, Landsiedel R, Ma-Hock L, Wiench K, Wohlleben W, van Ravenzwaay B. Tissue distribution and toxicity of intravenously administered titanium dioxide nanoparticles in rats. Arch Toxicol 2008, 82:151-157.

175. Ballou B, Lagerholm BC, Ernst LA, Bruchez MP, Waggoner AS. Noninvasive imaging of quantum dots in mice. Bioconjug Chem 2004, 15:79-86.

176. Bonoiu AC, Bergey EJ, Ding H, Hu R, Kumar R, Yong KT, Prasad PN, Mahajan S, Picchione KE, Bhattacharjee A, Ignatowski TA. Gold nanorod--siRNA induces efficient in vivo gene silencing in the rat hippocampus. Nanomedicine (Lond) 2011, 6:617-630.

177. Sabella S, Galeone A, Vecchio G, Cingolani R, Pompa PP. AuNPs are toxic in vitro and in vivo: a review. J Nanosci Lett 2011, 1:145-165.

178. Khlebtsov N, Dykman L. Biodistribution and toxicity of engineered gold nanoparticles: a review of in vitro and in vivo studies. Chem Soc Rev 2011, 40:1647-1671.

179. Sperling RA, Rivera GP, Zhang F, Zanella M, Parak WJ. Biological applications of gold nanoparticles. Chem Soc Rev 2008, 37:1896-1908.

180. Brown CL, Whitehouse MW, Tiekink ER, Bushell GR. Colloidal metallic gold is not bio-inert. Inflammopharmacology 2008, 16:133-137.

181. Chen Y-S, Hung Y-C, Liau I, Huang GS. Assessment of the in vivo toxicity of gold nanoparticles. Nanoscale Res Lett 2009, 4:858-864.

182. Hayashi A, Naseri A, Pennesi ME, Juan E. Subretinal delivery of immunoglobulin $G$ with gold nanoparticles in the rabbit eye. Jpn J Ophthalmol 2009, 53:249-256.

183. Rocha A, Zhou Y, Kundu S, Gonzalez JM, BradleighVinson S, Liang H. In vivo observation of gold nanoparticles in the central nervous system of Blaberus discoidalis. J Nanobiotechnology 2011, 9:9pp.

184. Trickler WJ, Lantz SM, Murdock RC, Schrand AM, Robinson BL, Newport GD, Schlager JJ, Oldenburg SJ, Paule MG, Slikker W, Jr., Hussain SM, Ali SF. Brain 
microvessel endothelial cells responses to gold nanoparticles: In vitro proinflammatory mediators and permeability. Nanotoxicology 2011, 5:479-492.

185. Park E-JC, Wan-Seob, Jeong J, Yi J-h, Choi K, Kim Y, Park K. Induction of inflammatory responses in mice treated with cerium oxide nanoparticles by intratracheal instillation. J Health Sci 2010, 56:387-396.

186. Sonavane G, Tomoda K, Makino K. Biodistribution of colloidal gold nanoparticles after intravenous administration: effect of particle size. Colloids Surf B Biointerfaces 2008, 66:274-280.

187. Balogh L, Nigavekar SS, Nair BM, Lesniak W, Zhang C, Sung LY, Kariapper MS, El-Jawahri A, Llanes M, Bolton B, Mamou F, Tan W, Hutson A, Minc L, Khan MK. Significant effect of size on the in vivo biodistribution of gold composite nanodevices in mouse tumor models. Nanomedicine 2007, 3:281-296.

188. Etame AB, Smith CA, Chan WCW, Rutka JT. Design and potential application of PEGylated gold nanoparticles with size-dependent permeation through brain microvasculature. Nanomedicine (New York, NY, U. S.) 2011, 7:992-1000.

189. Gaston B, Reilly J, Drazen JM, Fackler J, Ramdev P, Arnelle D, Mullins ME, Sugarbaker DJ, Chee C, Singel DJ. Endogenous nitrogen oxides and bronchodilator S-nitrosothiols in human airways. Proc Natl Acad Sci U S A 1993, 90:10957-10961.

190. Santos RR, Vermeulen S, Haritova A, Fink-Gremmels J. Isotherm modeling of organic activated bentonite and humic acid polymer used as mycotoxin adsorbents. Food Addit Contam, Part A 2011, 28:1578-1589.

191. Hongo M, Ohara S, Hirasawa Y, Abe S, Asaki S, Toyota T. Effect of lansoprazole on intragastric $\mathrm{pH}$. Comparison between morning and evening dosing. Dig Dis Sci 1992, 37:882-890.

192. Fallingborg J, Christensen LA, Jacobsen BA, Ingeman-Nielsen M, Rasmussen $\mathrm{HH}$, Abildgaard K, Rasmussen SN. Effect of olsalazine and mesalazine on intraluminal $\mathrm{pH}$ of the duodenum and proximal jejunum in healthy humans. Scand J Gastroenterol 1994, 29:498-500.

193. Bergstrom CA, Luthman K, Artursson P. Accuracy of calculated pH-dependent aqueous drug solubility. Eur J Pharm Sci 2004, 22:387-398.

194. Zarate N, Mohammed SD, O'Shaughnessy E, Newell M, Yazaki E, Williams NS, Lunniss PJ, Semler JR, Scott SM. Accurate localization of a fall in $\mathrm{pH}$ within the ileocecal region: validation using a dual-scintigraphic technique. Am J Physiol Gastrointest Liver Physiol 2010, 299:G1276-1286.

195. Chesler M. Regulation and modulation of pH in the brain. Physiol Rev 2003, 83:1183-1221.

196. Scott CC, Gruenberg J. Ion flux and the function of endosomes and lysosomes: $\mathrm{pH}$ is just the start. BioEssays 2011, 33:103-110.

197. Wojtkowiak JW, Verduzco D, Schramm KJ, Gillies RJ. Drug resistance and cellular adaptation to tumor acidic pH microenvironment. Mol Pharm 2011, 8:2032-2038. 
Figure Captions:

Figure 1. Interfacial double layers near colloidal particles. Collodial particle $=$ black sphere. Positive ions (pink). Negative ions (blue).

Figure 2. Results of SciFinder ${ }^{\circledR}$ searches of $A$ ) all publications of NPs and those using in vitro and in vivo study platforms, B) metal-based NP nervous system publications by metal, and C) metal-based NP nervous system studies by research platform.

Figure 3. Global NP patent activity for all NPs and selected metal-based NPs.

Figure 4. NP distribution into the brain, expressed as a percentage of the dose and time after NP administration. Red = Unable to find the NP in the brain or reported that it was not in the brain. Black = Brain NP can be attributed to its presence in the brain's vascular compartment and the report provides no evidence of NP distribution into brain parenchyma. Blue = Brain NP is too high to be attributed to its presence in the brain's vascular compartment but the report provides no evidence of NP distribution into brain parenchyma, so the NP could have been associated with BBB cells but did not enter brain parenchyma. Green $=$ The report provides evidence of NP distribution into brain parenchyma.

Figure 5. Influence of NP size on brain uptake. Panels A through E: The percentage of gold NP dose in rat or mouse brain. Panels $F$ and G: The percentage of the gold NP dose taken up into rat primary BMECs per mg protein. Panel $\mathrm{H}$ : The percentage of the gold NP dose that permeated through rat BMECs. Asterisks indicate NP sizes that were ${ }^{*}$ not detectible, ${ }^{* *}$ below control, or ${ }^{* * *}$ reported as 0 . The $\zeta$ potential of the PEG-coated gold NPs was - 2 to $-11 \mathrm{mV}$. The dendrimers were an acetamide PAMAM. Uptake in rat BMECs was conducted with primary cells. Rat brain permeation was through an endothelial and astrocyte cell co-culture. From: Panel A ${ }^{170}, B{ }^{186}, C{ }^{171}$, D and E ones ${ }^{187}, \mathrm{~F}$ and $\mathrm{G}{ }^{184}$, and $\mathrm{H}^{188}$. 
Figure 1.

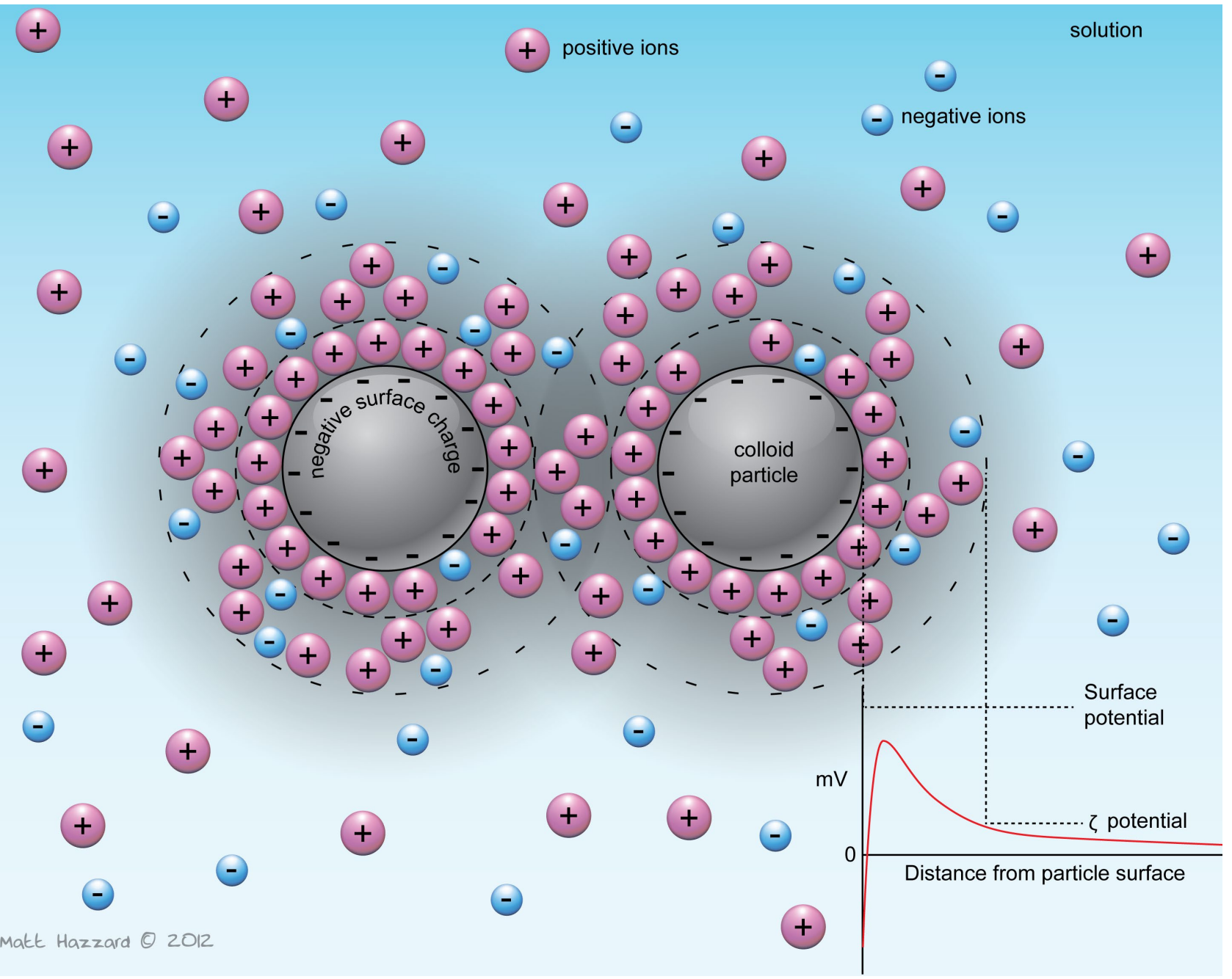


Figure 2.

A Nanoparticle Publications
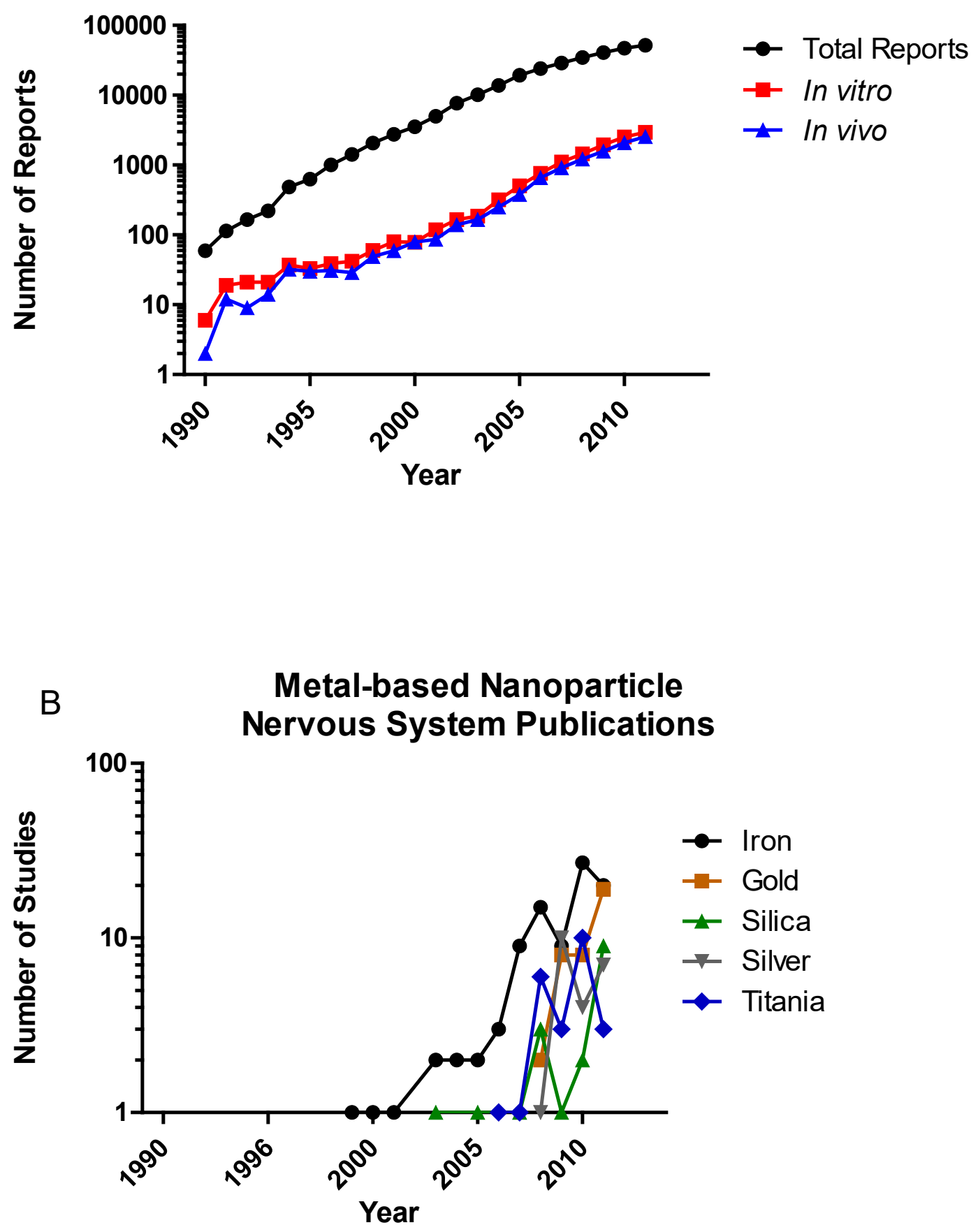
C Publications of Metal-based Nanoparticle in vitro and in vivo Nervous System Studies

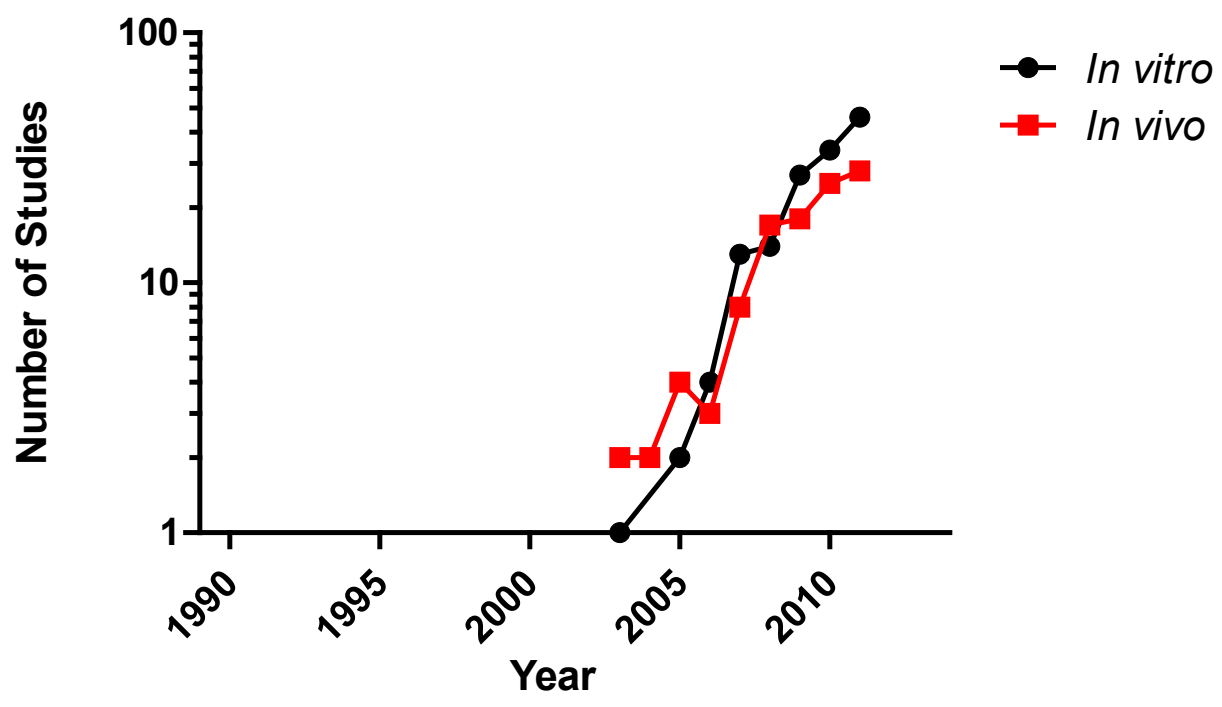


Figure 3.

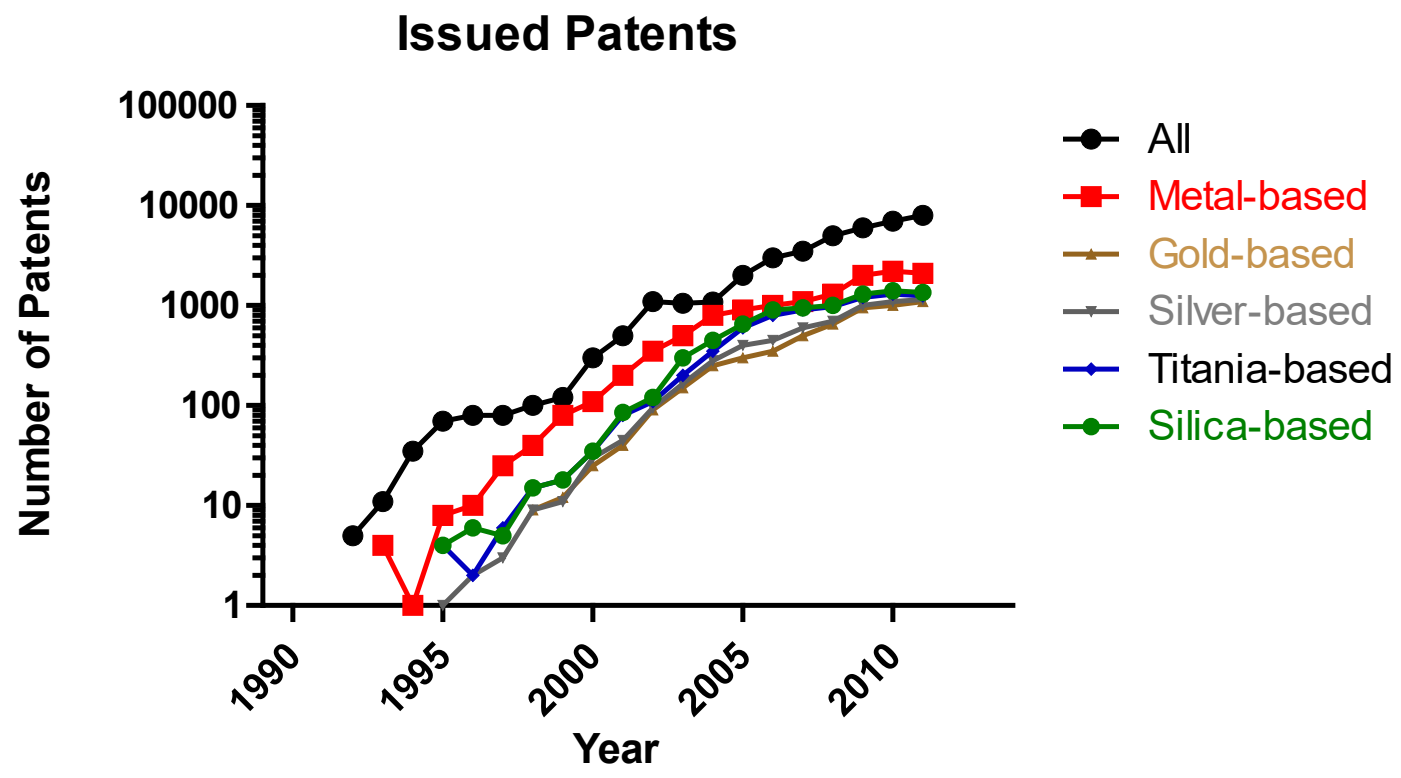


Figure 4.

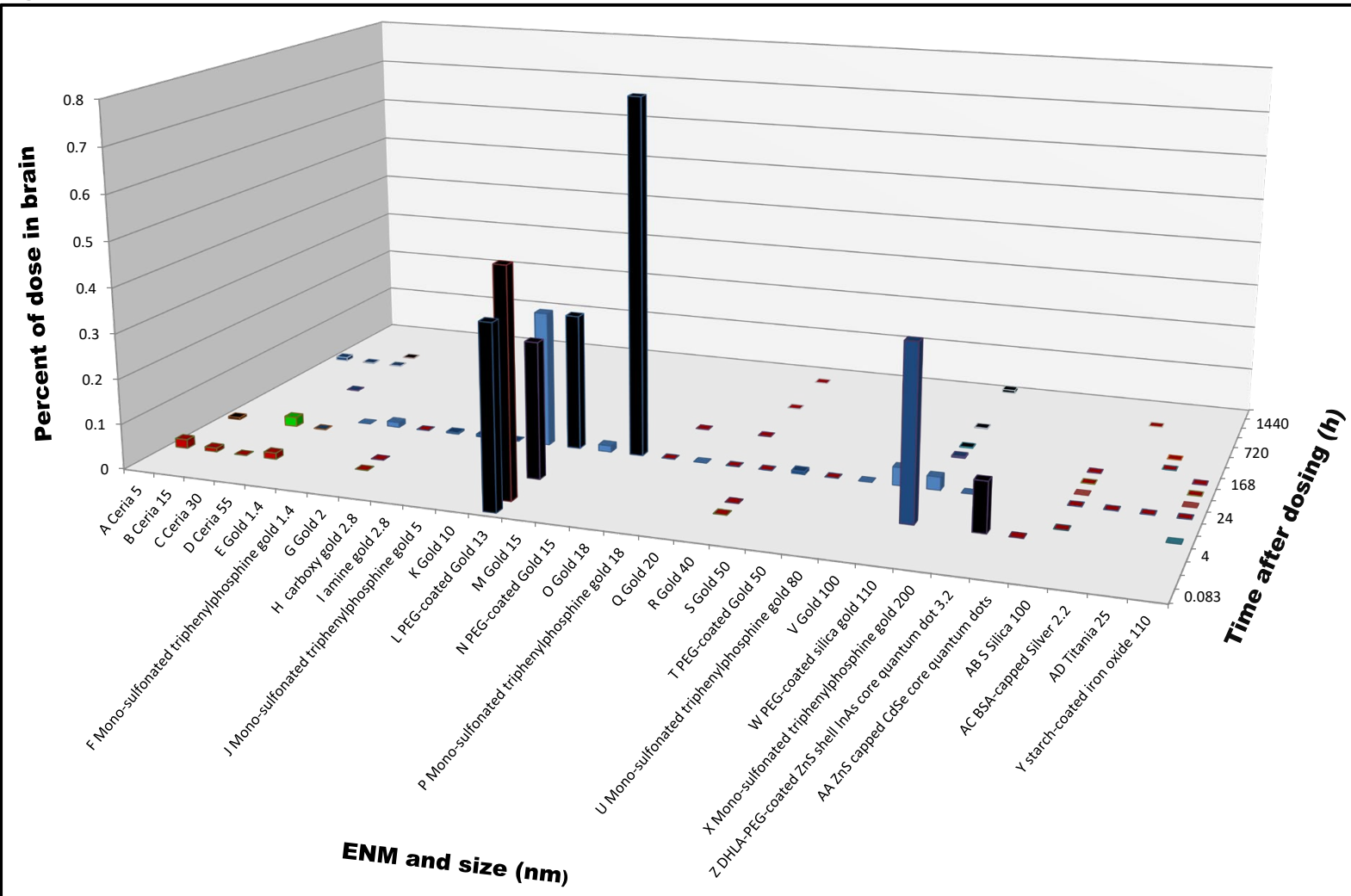


Figure 5. Dimple is upper casing first letter of appropriate words in titles above panels and $X$ and $Y$ axes

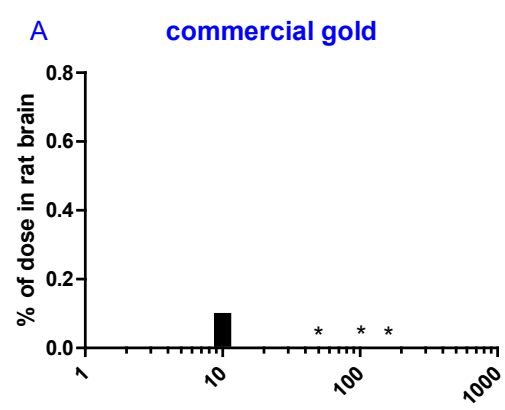

NP diameter (nm)

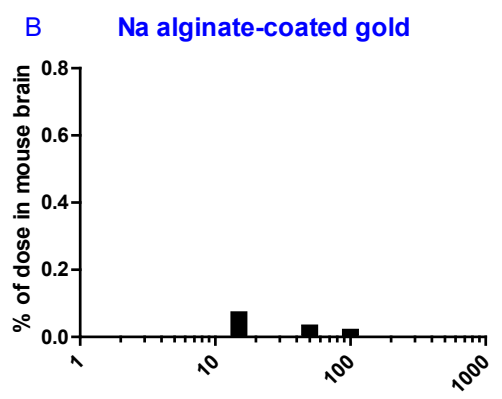

NP diameter (nm)

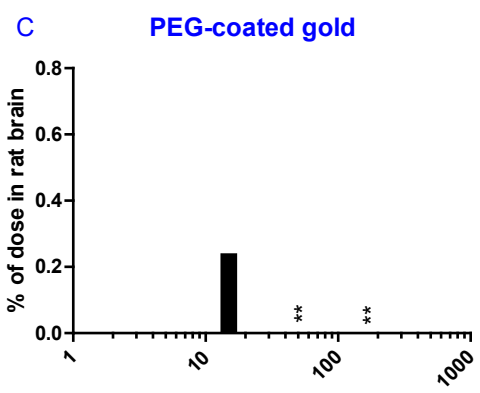

NP diameter (nm)
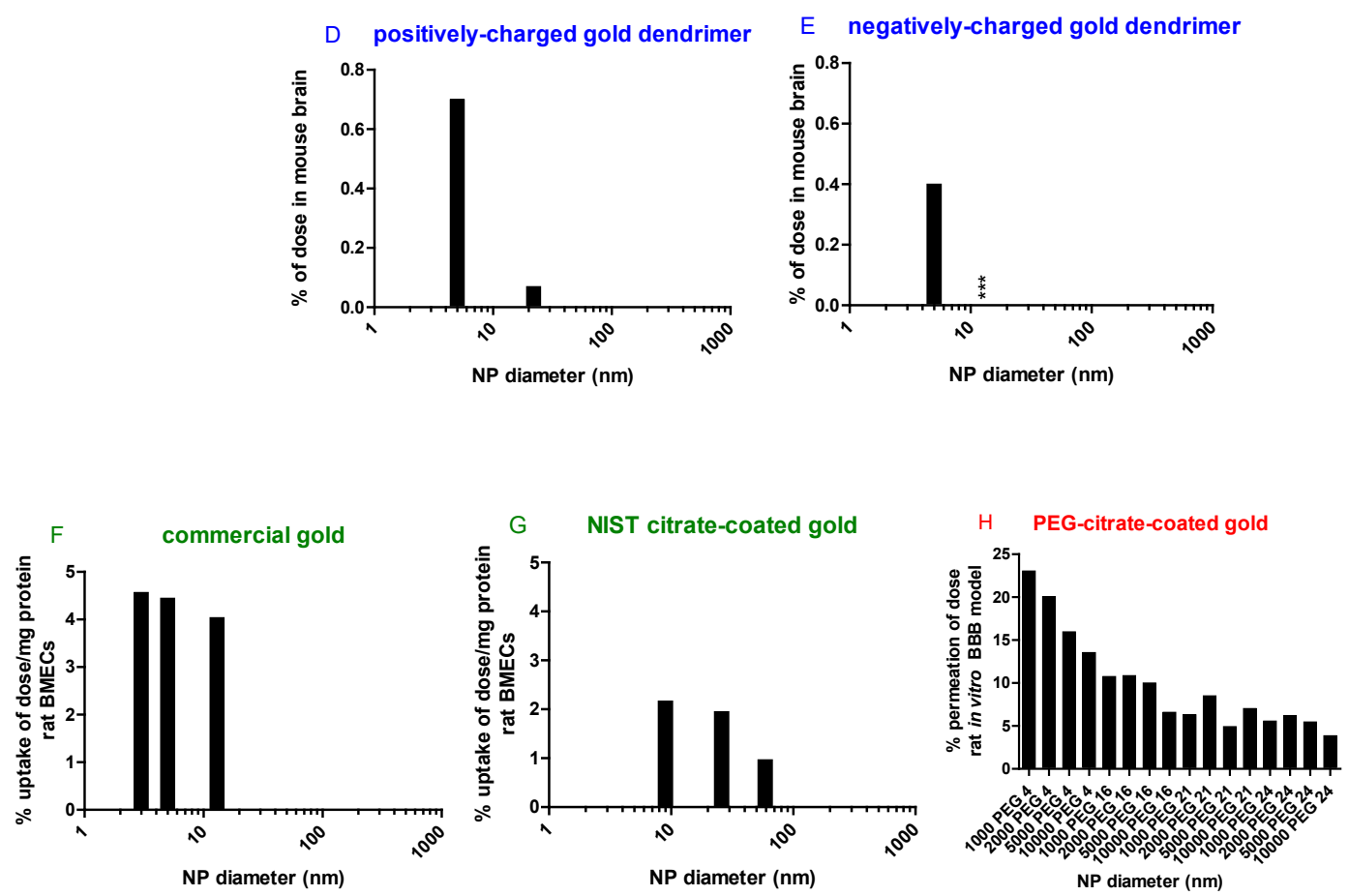
Table 1. The pH of some body fluids, organs and tumors.

\begin{tabular}{|l|l|l|}
\hline \multicolumn{1}{|c|}{ Site } & \multicolumn{1}{|c|}{ pH } & Reference \\
\hline Blood & 7.35 & 189 \\
\hline Lung bronchioalveolar fluid & 6.25 & 190 \\
\hline Oral cavity & 7.4 & 191 \\
\hline Stomach & $\begin{array}{l}1-2, \text { up to 4 during proton pump inhibitor } \\
\text { therapy }\end{array}$ & 192 \\
\hline Jejunum & 6.05 & 192 \\
\hline Duodenum & 6.25 & 193 \\
\hline Small intestine & 7.4 & 194 \\
\hline Ileum & 7.5 & 194 \\
\hline Cecum & 6 & 194 \\
\hline Large bowel & 5.7 & 196 \\
\hline Brain extracellular fluid & 7.3 & 196 \\
\hline Lysosome & 4.5 & 6 \\
\hline Endosome & 6.5 to 6.9 & \\
\hline Tumor (extracellular) & & \\
\hline
\end{tabular}

